\title{
Peripheral modulation of the endocannabinoid system in metabolic disease
}

Nirajan Shrestha ${ }^{1}$, James S.M. Cuffe ${ }^{1}$, Dana S. Hutchinson ${ }^{2}$, John P. Headrick ${ }^{1}$, Anthony V. Perkins ${ }^{1}$, Andrew J. McAinch ${ }^{3,4}$ and Deanne H. Hryciw ${ }^{3,5, *}$

${ }^{1}$ School of Medical Science, Menzies Health Institute Queensland, Griffith University, Gold Coast, QLD, Australia

${ }^{2}$ Drug Discovery Biology, Monash Institute of Pharmaceutical Sciences, Monash University, Parkville, VIC, Australia

${ }^{3}$ Centre for Chronic Disease, College of Health and Biomedicine, Victoria University, Melbourne, VIC, Australia

${ }^{4}$ Australian Institute of Musculoskeletal Science (AIMSS), College of Health and Biomedicine, Victoria University, Melbourne, VIC, Australia

${ }^{5}$ School of Natural Science, Menzies Health Institute Queensland, Griffith University, Nathan, QLD, Australia

${ }^{*}$ Corresponding author: Hryciw, D.H. (d.skelly@griffith.edu.au).

\section{Highlights:}

- The endocannabinoid system (ECS) is dysregulated in obesity-associated diseases

- $\mathrm{CB}_{1}$ antagonism is a potential therapeutic target for the treatment of obesity

- $\quad \mathrm{CB}_{1}$ antagonists have the potential for eliciting severe psychiatric side effects

- Antagonists of $\mathrm{CB}_{1}$ that do not cross the blood-brain barrier are in development

- Peripherally restricted $\mathrm{CB}_{1}$ antagonists are novel therapeutic targets for obesity

Teaser: This Keynote review discusses the peripheral modulation of the ECS in liver, adipose tissue, heart, skeletal muscle, gastrointestinal tract, pancreas, kidney and the immunoinflammatory system. 
Dysfunction of the endocannabinoid system (ECS) has been identified in metabolic disease. Cannabinoid receptor $1\left(\mathrm{CB}_{1}\right)$ is abundantly expressed in the brain but also expressed in the periphery. Cannabinoid receptor $2\left(\mathrm{CB}_{2}\right)$ is more abundant in the periphery, including the immune cells. In obesity, global antagonism of overexpressed $\mathrm{CB}_{1}$ reduces bodyweight but leads to centrally mediated adverse psychological outcomes. Emerging research in isolated cultured cells or tissues has demonstrated that targeting the endocannabinoid system in the periphery alleviates the pathologies associated with metabolic disease. Further, peripheral specific cannabinoid ligands can reverse aspects of the metabolic phenotype. This Keynote review will focus on current research on the functionality of peripheral modulation of the ECS for the treatment of obesity.

Keywords: Cannabinoid receptor; endocannabinoid system; peripherally restricted cannabinoid antagonist; obesity. 


\section{Introduction}

The prevalence of metabolic disorders has increased exponentially worldwide. Metabolic diseases are the result of excessive systemic adiposity (obesity), insulin resistance, type 2 diabetes mellitus (T2DM) and cardiovascular disease (CVD). Investigation of potential therapeutic treatments for metabolic disease has focused, in part, on targets that are modulated by fatty acids or their derivatives. The endocannabinoid system (ECS) is a lipidderived signaling system [1] that can modulate energy expenditure. The most extensively characterized of the cannabinoid $(\mathrm{CB})$ receptors are $\mathrm{CB}_{1}$ and $\mathrm{CB}_{2}[1]$. Endogenous agonists for these receptors are synthesized on demand and degraded via cellular uptake and enzymatic hydrolysis [2] (Figure 1). Herein, we discuss the recent advances in research regarding the roles of $\mathrm{CB}_{1}$ and $\mathrm{CB}_{2}$ in metabolic disease, and how pharmaceutical agents that act as ligands for these receptors can be used in the prevention and treatment of metabolic diseases through specific modulation in the periphery.

\section{$\mathrm{CB}_{1}$ and $\mathrm{CB}_{2}$}

The ECS comprises several ligands and two main receptors: $\mathrm{CB}_{1}$ and $\mathrm{CB}_{2} \cdot \mathrm{CB}_{1}$ are the most abundantly expressed G-protein-coupled receptor (GPCR) in the central nervous system (CNS) [3], with elevated expression in the hippocampus, cortex, cerebellum and basal ganglia. The main physiological function of $\mathrm{CB}_{1}$ is modulation of neurotransmission. $\mathrm{CB}_{1}$ has also been localized in the periphery, with expression in the dorsal root ganglion, myelinated nerve fiber bundles in the skin, macrophages, mast cells, the gastrointestinal system (predominantly in the cholinergic neurons of the myenteric), spleen, tonsils, leukocytes, skeletal muscle and renal cells [4]. By contrast, $\mathrm{CB}_{2}$ is predominately expressed in immune cells, particularly in the spleen, thymus and circulating immune cells [5]. In immune cells, $\mathrm{CB}_{2}$ mainly regulates 
immune responses and inflammation. In addition, $\mathrm{CB}_{2}$ is also expressed in skeletal, cardiovascular and renal systems. $\mathrm{CB}_{2}$ is also localized with low levels of expression in the CNS, mainly in the cell bodies and dendrites of the central neurons [6]. Furthermore, $\mathrm{CB}_{1}$ and $\mathrm{CB}_{2}$ are also expressed in osteoblasts and osteoclasts, where they stimulate bone formation and remodeling $[7,8]$.

In addition to $C B_{1}$ and $C B_{2}$, several other proteins have been suggested to be $C B$ receptors based on their ability to be activated by endocannabinoids or other CB ligands. These include GPR18 [9], GPR55 and GPR119 [10]. These receptors display little similarity to $\mathrm{CB}_{1}$ and $\mathrm{CB}_{2}$ but can be activated by $\mathrm{N}$-arachidonoylglycine, lysophosphatidylinositol and $\mathrm{N}$ oleoylethanolamide, respectively. However, there is no evidence that they can be activated by these ligands in vivo. As such, the International Union of Basic and Clinical Pharmacology Committee (IUPHAR) on Receptor Nomenclature and Drug Classification has not classified them as CB receptors and they have retained their orphan status. There is some evidence, however, that these receptors form heterodimers with CB receptors. GPR55 heterodimerizes with $\mathrm{CB}_{1}[11,12]$ and $\mathrm{CB}_{2}[13]$, which could have functional significance in tissues where both receptors are co-expressed. Together with other GPCRs, endocannabinoids or other CB ligands can activate transient receptor potential (TRP) channels [14], and potentiate glycine receptors [15].

\section{CB receptor ligands}

$\mathrm{CB}$ receptors are activated by two endogenous ligands [ $N$-arachidonoylethanolamine (AEA) and 2-arachidonoylglycerol (2-AG)], plant-derived cannabinoids [including tetrahydrocannabinol (THC)] and a range of synthetic ligands. Based on chemical structures, $\mathrm{CB}$ receptor agonists are subclassified into four groups. Classical CBs consist of tricyclic 
dibenzopyran derivatives that are either naturally extracted compounds of cannabis or synthetic analogs of these compounds. The most widely studied naturally isolated CBs are delta-9-tetrahydrocannabinol $(\Delta 9-\mathrm{THC})$ and $\Delta 8$-THC $[16,17] . \Delta 9-\mathrm{THC}$ has a similar affinity to $A E A$ for $C B_{1}$; however, it displays lower efficacy than $A E A$ at $C B_{2}$ than at $C B_{1}[18]$. The nonclassical CBs contain bicyclic and tricyclic analogs of $\triangle 9-T H C$, including 3-(2-hydroxy-4(1,1-dimethylheptyl)phenyl)-4-(3-hydroxypropyl)cyclohexanol (CP55,940), an agonist with similar affinities for both CB receptors [19]. The third group of CB receptor agonists are the aminoalkylindole cannabinoids, including $\quad(R)-(+)-[2,3-$ dihydro-5-methyl-3[(4morpholinyl)methyl]pyrrolo[1,2,3-de]-1,4-benzoxazinyl]-(1-naphthalenyl)methanone mesylate salt (WIN 55212). WIN 55212 has a high affinity for both receptor subtypes, with a slightly greater affinity for $\mathrm{CB}_{1}[17,20]$. The fourth group, eicosanoid $C B$ include $A E A[21]$ and 2-AG [22]. Among all eicosanoid CBs, 2-AG exhibits the highest intrinsic activities at $\mathrm{CB}_{1}$ and $\mathrm{CB}_{2}$. AEA has a lower affinity for $\mathrm{CB}$ receptors and acts as a partial agonist, exhibiting mixed agonist-antagonist properties at $\mathrm{CB}_{1}$ and $\mathrm{CB}_{2}$.

\section{CB receptor signaling}

$\mathrm{CB}$ receptors predominately couple to the inhibitory Gi/o $\mathrm{G}$ proteins, which inhibit adenylate cyclase activity and subsequently decrease intracellular cyclic AMP levels. However, as is common with many other GPCRs, pleotropic coupling of CB receptors to other effector proteins has been reported. These include activation of $\mathrm{Gq}$ and $\mathrm{Gs}$ proteins, $\beta$-arrestin recruitment, inhibition of voltage-gated calcium channels, stimulation of inwardly rectifying potassium currents and activation of mitogen-activated protein kinase (MAPK) signaling pathways, reviewed in [23]. Because CB receptors can couple or signal to multiple effector proteins, the likelihood of biased signaling to occur is increased. Biased signaling can be 
defined as ligand-dependent selectivity for specific signal transduction pathways following activation of the same receptor. It is thought to occur when different ligands bind to a receptor to cause different receptor conformations, enabling the receptor to preferentially signal to one pathway over another. Biased signaling at $\mathrm{CB}_{1}$ and $\mathrm{CB}_{2}$ has been reported (i.e., $[24,25]$ for $\mathrm{CB}_{1}$ and $[26,27]$ for $\left.\mathrm{CB}_{2}\right)$. The significance of biased signaling is attractive, in that theoretically one could design a drug with fewer side effects. However, further work is warranted in the $\mathrm{CB}$ receptor field to delineate those coupled signaling pathways that are beneficial or detrimental following $C B$ activation.

\section{Central dysfunction of the ECS in metabolic disease}

The ECS is well recognized to have a vital role in the regulation of eating behavior and energy homoeostasis [28-30]. In the brain, the ECS regulates food intake by modulating activity of the hypothalamus and the limbic system [31]. In the hypothalamus, endocannabinoids are released on demand after short-term food deprivation. Thereafter, the ECS transiently regulates food intake by enhancing orexigenic mediators such as ghrelin and inhibiting anorexigenic mediators, namely leptin and cholecystokinin [32-34]. Activation of $\mathrm{CB}_{1}$ by hypothalamic administration of AEA stimulates appetite [35], whereas inhibition of CB receptors by SR141716A (rimonabant) suppresses appetite [36].

Central dysfunction in the $\mathrm{CB}$ receptors has also been identified in metabolic disease. $\mathrm{CB}_{1}$ in the forebrain and in sympathetic neurons can regulate thermogenesis and energy balance [37]: conditional knockout mice lacking $\mathrm{CB}_{1}$ in forebrain neurons result in mice with a lean phenotype that are resistant to diet-induced obesity. Furthermore, $\mathrm{CB}_{1}$-deficient mice have increased energy expenditure [39]; and even following consumption of a high-fat diet (HFD) (49\% of energy as fat) $\mathrm{CB}_{1}$-deficient mice do not become obese [38]. 
Rimonabant, the most widely studied antagonist, has been shown to act as a $\mathrm{CB}_{1}$ antagonist and inverse agonist $[40,41]$. Rimonabant was developed and marketed for the treatment of obesity but was withdrawn from the market in 2008 owing to severe psychological side effects. These are thought to have occurred as a result of the ability of rimonabant to cross the blood-brain barrier to target central $\mathrm{CB}_{1}$, located in areas of the brain implicated in depression (prefontal and frontal cortex, hippocampus, cerebellum) and anhedonia (nucleus accumbens, dorsal striatum). $\mathrm{CB}_{1}$ antagonism ( $\mathrm{CB}_{1}$ knockout mice) also results in lower levels of several neurotransmitters, including serotonin, as reviewed in [42], which are thought to contribute to the adverse side effects observed. Thus, despite the adverse events with targeting the ECS centrally, the ability of this system to modulate food intake has led to more-recent research that has investigated peripheral modulation of $\mathrm{CB}_{1}$ as an obesity therapeutic.

\section{Peripheral modulation of $\mathrm{CB}_{1}$ and $\mathrm{CB}_{2}$}

Much of our understanding about the role of the CB receptors in normal physiology has come from studies focused on their activity in disease states. Crucial to the development of therapeutics targeting the peripheral CB system is an understanding about the role they take in numerous organs and systems. Importantly, several research studies have demonstrated links between the disruption of the ECS and metabolic disease. Specifically, altered expression of $\mathrm{CB}_{1}$ and $\mathrm{CB}_{2}$ has been identified in several tissues from obese animals (for review, see [43]). Typically, $\mathrm{CB}_{1}$ expression is increased in obesity in a tissue-specific manner, and $\mathrm{CB}_{2}$ expression is decreased in obesity [44,45]. Moreover, diet-induced obesity increases AEA and 2-AG concentrations in the brain and peripheral tissues of mice [46]. In a human study, circulating 2-AG levels were significantly elevated in obese compared with lean individuals 
and significantly correlated with body mass index (BMI), percent body fat and visceral fat in males and females [47]. In addition, plasma 2-AG but not AEA levels were positively correlated with cardio-metabolic risk factors, including intra-abdominal adiposity in obese men [48]. A recent study found that the circulating levels of 2-AG are higher in insulin-resistant compared with insulin-sensitive obese postmenopausal women [49]. Within the periphery, the ECS modulates the production of hormones from the gut and pancreas, and controls functions within the liver, adipose tissue, heart and skeletal muscle (Figure 2) - organs that are key to the progression of metabolic disease. Thus, several researchers have proposed that the development of peripherally restricted CB receptor antagonists could yield novel and exciting therapeutics in obesity $[50,51]$.

\section{Endocannabinoids and leptin signaling}

The adipokine leptin plays a key part in food intake, bodyweight control and metabolism. The main role of leptin is via the modulation of neuronal signaling pathways in the hypothalamus where it acts as an anorexigenic mediator of food intake, acting via the leptin receptor $\mathrm{Ob}-\mathrm{Rb}$ [52]. Because cannabinoids are orexigenic, hypothalamic concentrations of cannabinoids are inversely correlated with plasma concentrations of leptin [33]. Anorexigenic proopiomelanocortin (POMC) and orexigenic neuropeptide $\mathrm{Y}$ (NPY) expressing neurons in the arcuate nucleus (ARC) are potential targets for the action of leptin in the regulation of feeding behavior [53]. The peripheral $\mathrm{CB}_{1}$ antagonist JD5037 has recently been demonstrated to restore hypothalamic leptin sensitivity by activating anorexigenic POMC neurons [54], with JD5037 also demonstrated to reduce obesity by reversing leptin resistance in diet-induced obese (DIO) mice [55]. Further research has demonstrated that leptin directly inhibits endocannabinoid synthesis by reducing intracellular calcium levels and glucocorticoid- 
mediated CB release $[56,57]$. AEA is significantly reduced in white adipose tissues (WAT) following leptin infusion in rats [58]. In isolated human cytotrophoblasts, 2-AG downregulates leptin expression, which is reversed by $C_{1}$ and $C_{1}$ antagonists, suggesting that the 2-AG regulation of leptin expression is dependent on CB receptors [59].

\section{Mitochondrial modulation by CB signaling}

Metabolic disturbances such as diabetes and obesity are associated with altered mitochondrial respiratory function $[60,61]$. Importantly, endocannabinoids have been found to modulate mitochondrial morphology and membrane permeability [62]. AEA promotes mitochondrial swelling and membrane fluidity but downregulates cytochrome release and membrane potential $[63,64]$. In isolated rat liver mitochondria, AEA inhibits oxidative phosphorylation by blocking $F_{0} / F_{1}$ ATP synthase activity [65]. In addition, endocannabinoid, phytocannabinoid and synthetic $\mathrm{CB}$ receptor agonists such as $\mathrm{AEA}, \triangle 9-\mathrm{THC}$ and $\mathrm{HU} 210$ reduce mitochondrial oxygen consumption in a dose-dependent manner in rat heart mitochondria [66]. This study further demonstrated that $\mathrm{CB}_{1}$ agonists induce biphasic changes in complex I and/or complex II/III activities. In 2008, Tedesco et al. investigated the effects of $\mathrm{CB}_{1}$ deletion or antagonism in $\mathrm{W}$ and isolated mature white adipocytes of HFD mice ( $60 \% \mathrm{kcal}$ fat). They observed that $\mathrm{CB}_{1}$ deletion or chronic rimonabant treatment countered HFD-dependent reductions in endothelial nitric oxide synthase (eNOS) expression and mitochondrial biogenesis, an effect linked to reduced adiposity and bodyweight [67]. In addition, $\mathrm{CB}_{1}$ deletion or chronic rimonabant treatment on WAT and isolated mature white adipocytes of HFD mice countered HFD-dependent reductions in eNOS expression and mitochondrial biogenesis, an effect linked to reduced adiposity and bodyweight [68]. 
Recent research has demonstrated that $\mathrm{CB}_{1}$ is localized to muscle mitochondria [69]. In the mitochondria, $\mathrm{CB}_{1}$ activation with $\mathrm{THC}$ decreases mitochondria-coupled respiration, which was absent in $\mathrm{CB}_{1}$ knockout mice [69]. Specifically, $\mathrm{CB}_{1}$ is thought to be involved in the mitochondrial regulation of oxidative activity through enzymes responsible for the pyruvate metabolism pathway. $\mathrm{CB}_{1}$ is also present in the membrane of mouse neuronal mitochondria $\left(\mathrm{mtCB}_{1}\right)$ which regulates brain mitochondrial activity and energy metabolism [70]. Recent studies have demonstrated that genetic deletion of hippocampal $\mathrm{mtCB}_{1}$ prevents $\mathrm{CB}$-induced reduction in memory formation, suggesting that $\mathrm{mtCB}_{1}$ mediates memory processes through mitochondrial energy metabolism [71]. In addition, $\mathrm{CB}_{1}$ in mitochondria of $\mathrm{POMC}$ cells regulates mitochondrial adaptations and CB-induced feeding in Pomc-cre mice [72].

\section{ECS in the liver: lipid metabolism}

Despite low expression, $\mathrm{CB}_{1}$ is expressed in liver cells, including hepatic stellate cells (HSCs) $[73,74]$ and hepatocytes $[75] . \mathrm{CB}_{2}$ is undetectable in healthy liver tissue but is upregulated in pathological conditions such as non-alcoholic fatty liver disease (NAFLD) [76], hepatic fibrosis [77] and hepatocellular carcinoma (HCC) [78]. A recent human study demonstrated for the first time that serum levels of $2-A G$, but not $A E A$, are significantly increased in patients with NAFLD, independent of obesity status of the patient [79].

Several studies have suggested that targeting the ECS in the liver could have benefits in obesity. In rodents consuming a HFD, there is an increase in $\mathrm{CB}_{1}$ protein expression in purified liver plasma membranes. Further, agonism of $\mathrm{CB}_{1}$ in mice consuming a standard chow diet elevates de novo lipogenesis via sterol regulatory element binding protein-1c (SREBP-1c), a lipogenic transcription factor regulating fatty acid synthase (FAS) and other lipogenic enzymes [80]. The mechanism for this is a reduction in fatty acid amide hydrolase (FAAH) 
which is likely to be independent of the central modulation of the ECS. This study was supported by later work that confirmed a reduced rate of de novo lipogenesis in the liver of specific $\mathrm{CB}_{1}$ knockout mice [81]. In a diet-induced obesity mouse model, $\mathrm{CB}_{1}$ antagonism improves liver steatosis and lipid handling [82]; and in obese Zucker fa/fa rats $\mathrm{CB}_{1}$ antagonism reverses liver steatosis and reduces steatohepatitis-associated high liver tumor necrosis factor (TNF)- $\alpha$ levels [83]. These findings have been supported by in vitro studies in hepatic cells, which demonstrate an improved lipogenesis after $\mathrm{CB}_{1}$ antagonist treatment $[84,85]$. Reversal of HFD-induced hepatic steatosis and fibrosis by $\mathrm{CB}_{1}$ antagonism is mediated by adiponectin via increasing fatty acid oxidation and reducing free fatty acid uptake into the liver [86]. Hepatic $\mathrm{CB}_{1}$ is necessary for HFD-induced hepatic insulin resistance because hepatocyte-specific $\mathrm{CB}_{1}$ knockout mice receiving $\mathrm{HFD}$ remain insulin sensitive [87]. Studies have also shown that hepatic insulin resistance induced by HFD in murine models is mediated by $\mathrm{CB}_{1}$-dependent activation of the long-chain ceramide synthesis in liver [88]. These findings suggest hepatic $\mathrm{CB}_{1}$ as a potential therapeutic target for obesity-associated insulin resistance.

In humans, $\mathrm{CB}_{2}$ is increased in individuals with liver disease [76]. Several studies report that $\mathrm{CB}_{2}$ agonists increase the extent of hepatic steatosis $[89,90] . \mathrm{CB}_{2}$ agonist JWH133 enhanced HFD-induced hepatic steatosis in wild-type mice; however, the effect was blunted in $\mathrm{CB}_{2}$-deficient mice [89]. An in vitro study demonstrated that $\mathrm{CB}_{2}$-selective agonist $A M 1241$ increases the degree of steatosis in oleic-acid-treated fatty hepatocytes [90]. Thus, targeting the ECS in the liver directly can modulate disease phenotype.

\section{ECS in adipose tissue}

Adipose tissue contributes to the regulation of many physiological processes, and dysfunction fundamentally underpins obesity and related co-morbidities [91]. Further, this endocrine 
organ produces physiologically important proteins such as leptin, lipoprotein lipase and adiponectin [92]. Several studies suggest that endocannabinoids directly regulate lipid metabolism in adipose tissues in vitro $[33,93]$. Indeed, $\mathrm{CB}_{1}$ is expressed in adipose tissue and elevated during adipogenesis $[30,47,93] . \mathrm{CB}_{1}$ is expressed in epidymal adipose tissue and adipocytes and $\mathrm{CB}_{1}$ agonists increase adipocyte lipoprotein lipase (LPL) activity dosedependently in primary adipocyte cultures, whereas rimonabant reduces this effect [93]. Rimonabant also stimulates adiponectin expression in cultured adipocyte cells and reduces hyperinsulinemia in obese rats [44]. Interestingly, $\mathrm{CB}_{1}$ expression and FAAH were elevated in mature human adipocytes compared with preadipocytes [94], suggesting an important yet undiscovered role for the ECS in functional adipocytes. Cable et al. reported a correlation between the endocannabinoid metabolizing enzyme FAAH and bodyweight in subcutaneous adipocytes in metabolically healthy humans. However, another catabolic enzyme: monoacylglycerol lipase (MAGL), does not correlate with bodyweight [95]. Thus, the relationship between bodyweight and the expression of components of the ECS in adipose tissue might not be straightforward. Furthermore, agonism of $\mathrm{CB}_{1}$ enhances while rimonabant reduces insulin sensitivity in cultured adipocytes [96]. It is unlikely that this is via the modulation of glucose homeostasis because activation of endocannabinoids in human adipocytes promotes GLUT4 translocation and glucose uptake independently of insulin [97].

A recent study identified that peripheral antagonism of $\mathrm{CB}_{1}$ in adipocytes enhances transdifferentiation of white adipocytes to the brown fat phenotype which would improve metabolism via enhancing thermogenesis [98]. In addition, chronic $\mathrm{CB}_{1}$ antagonism activates brown adipose tissue (BAT) thermogenesis and enhances energy expenditure and glucose utilization in DIO mice [99]. 
ECS in the heart: role in cardiovascular disease

Obesity increases the risk of co-morbidities including cardiovascular disease, increasing the risk of developing ischemic heart disease [100]. Endocannabinoids have been studied in cardiac ischemia-reperfusion (I/R) injury. 2-AG and palmitoylethanolamide (PEA), but not $A E A$, protected the isolated rat heart against ischemia through agonism of $\mathrm{CB}_{2}$ [101]. Other studies have supported the role for $\mathrm{CB}_{2}$ but not $\mathrm{CB}_{1}$ in myocardial I/R injury [102-105]. In isolated cardiomyocytes, treatment with rimonabant decreases transforming growth factor (TGF)- $\beta 1$ fibrosis [106], suggesting that $\mathrm{CB}_{1}$ antagonism does have a direct benefit to the heart.

In addition to ischemic heart disease, the ECS has been shown to play a major part in atherosclerosis $[107,108]$. Low-dose CB therapy reduces the progression of atherosclerosis in mice, predominantly by inhibiting macrophage recruitment [107]. Increased levels of 2-AG were reported in aortas and visceral adipose tissue in the pro-atherosclerotic model of ApoE null mice fed a high cholesterol diet, although $\mathrm{CB}_{2}$ antagonism did not affect plaque formation [108]. However, $\mathrm{CB}_{1}$ antagonism with rimonabant reduced atherosclerosis development in the aortic sinus in low-density lipoprotein (LDL)-receptor-deficient mice through antiinflammatory effects [109]. In addition, rimonabant improves endothelial dysfunction by decreasing reactive oxygen species (ROS) production in the vessel wall of ApoE null mice fed a cholesterol-rich diet, although atherosclerotic plaque formation was not reduced [110].

In contrast to effects of $\mathrm{CB}_{1}$ activation, selective agonism of $\mathrm{CB}_{2}$ reduces atherosclerosis. For instance, the selective $\mathrm{CB}_{2} \mathrm{R}$ agonist JWH015 reduced monocyte migration by reducing chemokine receptor expression in human cultured myocytes, which is generally upregulated in inflammation-mediated atherosclerosis [111]. Similarly, the $\mathrm{CB}_{2}$ agonist JWH133 decreased atherosclerotic lesion formation, improved endothelial function 
and reduced ROS levels in high-cholesterol-fed ApoE null mice. Interestingly, $A p o E$ and $\mathrm{CB}_{2}$ double knockout mice developed inflammatory cell infiltration in atherosclerotic plaques compared with ApoE null mice, suggesting a protective role of $\mathrm{CB}_{2}$ in atherosclerosis [112]. Furthermore, in vitro analysis has shown that $\mathrm{CB}_{2}$ activation reduces TNF- $\alpha$-induced proliferation and migration of human vascular smooth muscle cells [113]. More recently, Netherland-Van Dyke et al. investigated the effects of $C B$ receptor agonists on the development of atherosclerosis in $\mathrm{CB}_{2}{ }^{+/+}$and $\mathrm{CB}_{2}{ }^{-/-} \mathrm{LDL}$ receptor null mice and observed that lesional apoptosis and macrophage accumulation is $\mathrm{CB}_{2}$ dependent [114]. These data provide strong evidence regarding the opposing roles of $\mathrm{CB}_{1}$ and $\mathrm{CB}_{2}$ in cardiovascular disease, suggesting selective $C_{2}$ activation and $C_{1}$ antagonism as an attractive target for the treatment of atherosclerosis.

ECS in the skeletal muscle: insulin sensitivity

It is now well accepted that the components of the ECS are expressed in muscle cells [115]. Specifically, $\mathrm{CB}_{1}, \mathrm{CB}_{2}$ and $\mathrm{FAAH}$ are expressed in human and rodent skeletal muscle [116]. The first study to investigate the role of the ECS in skeletal muscle showed that the $\mathrm{CB}_{1}$ antagonist rimonabant increases glucose uptake in isolated soleus muscle from Lep ${ }^{\mathrm{ob}} /$ Lep $^{\mathrm{ob}}$ mice [117]. Further, in isolated cells AEA modulates skeletal muscle oxidative pathways [115]. However, not all the effects of $A E A$ are sensitive to $C B_{1}$ antagonism, suggesting the presence of other $\mathrm{CB}$ receptors [115]. $\mathrm{CB}_{1}$ expression is increased in the soleus muscle of HFD-fed mice [34], with Lindborg et al. reporting a decreased $\mathrm{CB}_{1}$ expression in the soleus of insulin-resistant obese Zucker rats compared with lean controls [118]. Similarly, $\mathrm{CB}_{2}$ expression is decreased and MAGL expression upregulated in skeletal muscle of HFD-fed rats [119]. A recent study suggested that dietary intake rather than the presence of obesity influenced ECS activity in 
skeletal muscle, because a HFD was shown to downregulate muscle $\mathrm{CB}_{1}$ and MAGL mRNA expression in normal and obese individuals, whether obesity was present or not [120]. Further, high n-3 PUFA intake increases expression of $\mathrm{CB}_{1}, \mathrm{CB}_{2}$ and $\mathrm{EC}$ synthesis enzymes in quadriceps muscles [121]. This suggests that the n-3 PUFA intake controlled the expression of the ECS.

Skeletal muscle accounts for $\sim 70-90 \%$ of total glucose disposal under post-prandial conditions $[122,123] . \mathrm{CB}_{1}$ plays an important part in the development of insulin resistance in skeletal muscle. AEA and adipocyte conditioned medium (CM) impairs insulin-stimulated Akt (ser473) phosphorylation in a $\mathrm{CB}_{1}$-dependent manner in cultures of skeletal muscle cells [124]. Insulin-stimulated glucose transport is significantly increased in the isolated soleus muscle following the chronic treatment of rimonabant [125]. Mechanistically, Lipina et al. found that the mixed $\mathrm{CB}_{1} / \mathrm{CB}_{2}$ agonist WIN 55,212-2 downregulates insulin-stimulated ERK1/2 but not Akt activation in cultured skeletal muscle cells, whereas rimonabant sensitizes Akt and ERK1/2 signaling in myotubes, suggesting a role for the ECS in regulating muscle metabolism and function [126].

\section{ECS in the gastrointestinal tract}

The role of the ECS in the gastrointestinal tract is generally associated with feeding behavior [127-129]; however, it could also play an important part in regulating gut inflammation and thus permeability. Mechoulam et al. first provided evidence of the ECS in the gastrointestinal tract in 1995, detecting 2-AG but not AEA in canine gut [130]. Later, Izzo et al. demonstrated that $A E A$ and 2-AG were present in the mouse small intestine [131]. $C B_{1}$ is present in normal colonic epithelium, smooth muscle and the submucosal myenteric plexus, $\mathrm{CB}_{1}$ and $\mathrm{CB}_{2}$ are 
expressed on plasma cells in the lamina propria and $\mathrm{CB}_{2}$ was present on gut-associated macrophages [132].

The main function of $\mathrm{CBs}$ in the gastrointestinal tract could be via the modulation of hormones that regulate hunger, with $\mathrm{CB}_{1}$ and $\mathrm{CB}_{2}$ co-localized with peptides regulating appetite in the gastrointestinal tract. Ghrelin, a circulating 28 amino acid peptide, is an orexigenic and adipogenic hormone [133]. During food deprivation, ghrelin levels increase while leptin levels decrease [133]. The orexigenic effects of ghrelin are mediated by AMPactivated protein kinase (AMPK) and are associated with central and peripheral metabolic effects [134]. Tucci et al. demonstrated that rimonabant can inhibit the orexigenic effect of ghrelin [135] and the same group reported no orexigenic effect of ghrelin in $\mathrm{CB}_{1}$ knockout mice, providing strong evidence for $\mathrm{CB}_{1}$ dependence of ghrelin effects on AMPK activity [32].

Recently, Alen et al. reported that peripheral $\mathrm{CB}_{1}$ antagonism with $\mathrm{LH}-21$ counteracted the orexigenic effects of ghrelin in rats [136]; however the exact mechanism remains unclear, although gastric $\mathrm{CB}_{1}$ modulates ghrelin production through a mammalian target of rapamycin (mTOR) pathway [137]. Importantly, Kola et al. suggested that the metabolic effect of ghrelin on AMPK in peripheral tissues is abolished in the absence of functional $\mathrm{CB}_{1}$, involving direct peripheral and central effects [138]. In addition, the gastrointestinal-secreted anorexigenic peptide hormone cholecystokinin (CCK) is also linked with the ECS, with CCK downregulating $\mathrm{CB}_{1}$ expression [139]. Thus, endocannabinoids could mediate satiety signaling from the gastrointestinal tract.

\section{ECS in the pancreas}

$\mathrm{CB}_{1}$ and $\mathrm{CB}_{2}$ are both present in the islets of Langerhans, where $\mathrm{CB}_{1}$ localizes predominantly to $\alpha$ cells and $\mathrm{CB}_{2}$ is found in $\alpha$ cells and insulin-containing $\beta$ cells $[140,141]$. In vitro 
stimulation of $\mathrm{CB}_{1}$ in $\beta$ cells enhances basal and glucose-stimulated insulin secretion [141,142]; however, $\mathrm{CB}_{2}$ agonism lowers glucose-dependent insulin secretion [141]. Rimonabant reportedly decreases basal insulin hypersecretion in isolated obese rat islets without affecting basal secretion in islets from lean rats [143]. By contrast, Li et al. reported that $\mathrm{CB}_{1}$ and $\mathrm{CB}_{2}$ antagonists fail to inhibit insulin secretion, suggesting involvement of $C B$ receptor-independent pathways in effects of some cannabinoids [144]. Kim et al. observed that $\mathrm{CB}_{1}$ blockade enhanced insulin receptor signaling in $\beta$ cells through the insulin receptor substrate 2-Akt pathway, and increased $\beta$ cell proliferation and reduced blood glucose in $d b / d b$ mice [145]. These contrasting results regarding the effects of CB receptor agonists and antagonists on insulin secretion warrant further studies. Recently, studies have reported that peripheral blockade of $\mathrm{CB}_{1}$ reverses macrophage infiltration in Zucker diabetic fatty (ZDF) rats and selective knockdown of macrophage $\mathrm{CB}_{1}$ mitigates $T 2 \mathrm{DM}$, suggesting macrophageexpressed $\mathrm{CB}_{1}$ as a potential target for the management of T2DM [146]. The same group later generated $\mathrm{CB}_{1}$-deficient rats on $\mathrm{ZDF}$ background to observe whether there is an obligatory role of $C_{1}$ in T2DM. They have identified that $C B_{1}$-deficient ZDF rats have improved $\beta$ cell function and hyperglycemia [147].

\section{ECS in renal function}

Deutsch and Chin initially proposed the presence of the ECS in the renal system in 1993, reporting amidase activity in rat kidneys [148]. Studies confirm the presence of $C_{1}$ throughout the nephron, including within the glomerulus [149,150], arterioles [151], tubules [152], loop of Henle [153], collecting ducts [154] and interstitium [152]. The ECS could play a part in normal tubular physiology because proximal tubule cells (PCT) express $C_{1}$ and $C_{2}$ [155]. 
It is well known that obesity is associated with developing end-stage renal disease $[156,157]$. Several studies have explored the role of ECS in obesity-linked kidney disease $[158,159] . \mathrm{CB}_{1}$ is elevated in kidneys from obese rats [158], and $\mathrm{CB}_{2}$ is downregulated in the kidneys of obese rats [160]. Further, $\mathrm{CB}_{1}$ antagonism improves renal function, presumably by a reduction in bodyweight. Jenkin et al. found that chronic $\mathrm{CB}_{1}$ antagonism improves albuminuria and renal tubular structure in diet-induced obese rats [158]. The effect of CBs in renal function could be mediated through specific renal cell types. The role of $\mathrm{CB}_{1}$ in renal proximal tubular cells (RPTCs) in obesity-induced renal dysfunction in RPTC-specific $\mathrm{CB}_{1}$ knockout $\left(\mathrm{RPTC} \mathrm{CB}_{1} \mathrm{R}^{-/-}\right.$) mice has been recently examined. This study found that $\mathrm{RPTC} \mathrm{CB}_{1} \mathrm{R}^{-/-}$ mice are protected from obesity-induced lipid accumulation in the kidney, kidney injury, renal inflammation and fibrosis through the liver kinase B1/AMP-activated protein kinase pathway, suggesting the specific role of RPTCs in $\mathrm{CB}_{1}$-mediated nephropathy [159]. Furthermore, the $\mathrm{CB}_{2}$ agonist $\mathrm{AM} 1241$ improves obesity-related renal dysfunction, whereas $\mathrm{CB}_{2}$ antagonism reduces creatinine clearance and increases kidney weight leading to renal dysfunction in dietinduced obese rats [160]. Importantly, $\mathrm{CB}_{2}$ agonism improves renal fibrosis and function, independent to any change in bodyweight [160]. Mechanistically, this could be via a reduction in circulating leptin concentrations, occurring in the absence of a reduction in bodyweight. Within the kidney, $\mathrm{CB}_{2}$ expression is downregulated by high concentrations of albumin [161], suggesting that, under normal physiological conditions, $\mathrm{CB}_{2}$ plays a part in protein handling by the kidney. Collectively, these studies provide strong evidence for the therapeutic potential of targeting $\mathrm{CB}_{1}$ and $\mathrm{CB}_{2}$ in the treatment of obesity-related renal diseases. 
The effects of the ECS in these different peripheral organ systems could involve modulation of the immune system and inflammation [57,162-164]. Obesity is characterized by chronic low-grade inflammation, an effect that reinforces the obesogenic phenotype (e.g., inducing insulin-resistance) and increases risk of obesity-related diseases including atherosclerosis and T2DM. These important inflammatory processes are responsive to the endocannabinoid system and $\mathrm{CB}$ antagonism.

The beneficial effects of $\mathrm{CB}_{1}$ antagonism in obese patients are attributed in part to an increase of anti-inflammatory and metabo-regulatory adiponectin [165], together with adiponectin receptors [166] in peripheral tissues. Experimental studies confirm a $\mathrm{CB}_{1}$ dependent stimulatory effect of endocannabinoids on adipose tissue adiponectin $[44,167]$, whereas endocannabinoids act via $\mathrm{CB}_{1}$ to suppress proinflammatory cytokines (MIP-1 $1 \beta$ and IL-7) in association with upregulation of adiponectin in adipose tissue of obese subjects [168]. Beneficial effects of $\mathrm{CB}_{1}$ antagonism on HFD-induced hepatic steatosis and fibrosis (but not improved adiposity and glycemic control) are adiponectin-receptor-dependent in mice [86]. Vascular dysfunction and atherosclerosis in obesity could also be responsive to antiinflammatory actions of the ECS, with activation of $\mathrm{CB}_{2}$ shown to limit TNF- $\alpha$-induced human endothelial cell activation, adhesion and transendothelial migration of monocytes [169], and $\mathrm{CB}_{1}$ and/or $\mathrm{CB}_{2}$ is implicated in inhibiting endothelial inflammatory responses and TNF- $\alpha-$ dependent vascular smooth muscle cell proliferation and migration (important in atherosclerosis) $[113,170]$.

Circulating endocannabinoid levels appear to be modulated in disease states associated with inflammation. Proinflammatory cytokines upregulate $\mathrm{CB}_{1}$ and $\mathrm{CB}_{2}$ expression in whole blood and mononuclear cells $[171]$ and $\mathrm{CB}_{1}$ in $\mathrm{T}$ lymphocytes $[172,173] . \mathrm{CB}_{1}$ and $\mathrm{CB}_{2}$ expression can be differentially regulated in association with altered cytokine levels in 
inflammatory disease models $[174,175]$. Coupled with generally anti-inflammatory actions of the ECS, such observations support a regulatory feedback loop between inflammatory activation and the ECS. Indeed, endocannabinoids have been shown to suppress excess inflammation in experimental models of hepatic ischemia [176,177], LPS-dependent pulmonary inflammation [178], inflammatory pain $[179,180]$, polymicrobial sepsis [181] and multiple sclerosis [182]. This feedback control of inflammatory cell recruitment and inflammatory mediator release by the ECS, which is potentially disrupted in disease, presents a potential therapeutic target.

Activation of $\mathrm{CB}_{1}$ and $\mathrm{CB}_{2}$ regulates cell migration and cytokine and chemokine production, with $\mathrm{CB}_{2}$ activation by 2-AG inhibiting migratory activities of immune cells $[183,184]$. AEA also inhibits production of proinflammatory cytokines, so that it reduces human monocyte interleukin (IL)-6 and IL-8 [185]; and IL-2, TNF- $\alpha$ and interferon (IFN)- $\nu$ from activated human $\mathrm{T}$ lymphocytes [186]. In T cells, $\mathrm{CB}_{2}$ activity can inhibit proliferation and release of IL-2, TNF- $\alpha$, IL-17 and IFN- $\gamma$ [186], and reduce differentiation and IL-17 release in T helper cells [187]. 2-AG also inhibits chemokine-induced chemotaxis of T cells [188]. In B cells, $\mathrm{CB}_{2}$ activity promotes homing and retention to marginal zone in $\mathrm{T}$-independent immune responses [189,190], modulates immunoglobulin class switching [191] and maintains germinal center $B$ cells in T-dependent immunity [192]. In macrophages, $C_{2}$ inhibits production of proinflammatory cytokines including IL-6, TNF- $\alpha$ and high mobility group box (HMGB)1 [193].

Despite evidence of anti-inflammatory effects of endocannabinoids, there is nevertheless evidence for proinflammatory effects in settings of doxorubicin-induced cardiomyopathy [194], nephropathy [194] and experimental dermatitis [195]. Endocannabinoids can also increase activated leukocyte function, and 2-AG could play a part 
in leukocyte recruitment and inflammatory mediator release [196]. Interestingly, proinflammatory effects are more consistently linked to 2-AG rather than AEA, which, coupled with lack of effect of $\mathrm{CB}$ receptor agonists on leukocyte function in models of inflammation, suggests these stimulatory effects of endocannabinoids could be receptor independent and involve metabolite effects.

\section{Development of peripheral specific CB ligands}

Owing to the adverse effects of centrally targeted therapeutics, emerging research has focused on ligands that do not cross the blood-brain barrier. Several therapeutics have been developed that specifically antagonize $\mathrm{CB}_{1}$ in the periphery. For example, the non-brainpenetrant neutral $\mathrm{CB}_{1}$ antagonist $\mathrm{AM} 6545$ reduces food intake and bodyweight in rodents consuming a chow diet [197] and blocks hyperphagia in western-diet-induced obese mice [198]. AM6545 also improves leptin sensitivity and reduces adiposity in DIO mice [199]. It further reduces corticosterone-induced adiposity and attenuates the metabolic phenotype induced by corticosterone [200]. Furthermore, another compound: JD5037, a peripherally restricted $\mathrm{CB}_{1}$ inverse agonist, decreases adipose tissue leptin secretion [55], which leads to a reversal of hypothalamic leptin resistance in diet-induced obese mice. JD5037 is also found to be effective in reducing bodyweight, hyperphagia and adiposity in an obese Mage/2-null mouse model, an established experimental model for Prader-Willi syndrome (PWS), proposing a potential strategy for the management of obesity in PWS [201]. Finally, LH-21, a neutral $\mathrm{CB}_{1}$ antagonist with poor brain penetration, has also been shown to reduce food intake [202], decrease leptin expression in visceral adipose tissue of diet-induced obese rats [68] and block the orexigenic effect of ghrelin [136]. Thus, research using several peripherally 
acting $\mathrm{CB}_{1}$ ligands suggests its central effects do not solely control the benefit of targeting this receptor in obesity.

Recent development in the area of $\mathrm{CB}$ therapeutics has led to the identification of drugs that can target $\mathrm{CB}_{1}$ in the periphery as well as $\mathrm{CB}_{2}$. Limited investigations have demonstrated the $\mathrm{CB}_{1} / \mathrm{CB}_{2}$ dual agonist $\mathrm{CB}-13$ can inhibit cardiomyocyte hypertrophy via AMPK-eNOS signaling in isolated rodent neonatal cardiomyocytes [203]. In an additional study, a peripherally restricted $\mathrm{CB}_{1} / \mathrm{CB}_{2}$ dual agonist naphthalen-1-yl-(4pentyloxynaphthalen-1-yl)methanone (SAB378), in a whole mouse model of experimental colitis [204], inhibited colonic propulsion in $\mathrm{CB}_{1}$ knockout mice, but not $\mathrm{CB}_{2}$ knockout mice. Thus, these data suggest that targeting the ECS in the gastrointestinal tract is beneficial.

One significant limitation in these studies, in terms of the development of therapeutics for metabolic disease, is the observation that in obesity $\mathrm{CB}_{1}$ is upregulated, whereas $\mathrm{CB}_{2}$ is downregulated [158]. Therapeutics that act as dual agonists could therefore have mixed or limited efficacies. In this therapeutic area, a more relevant therapeutic would be to antagonize $\mathrm{CB}_{1}$ and agonize $\mathrm{CB}_{2}$. Recent investigations of the previously characterized $\mathrm{CB}_{2}$ agonists: GW405833 [1-(2,3-dichlorobenzoyl)-5-methoxy-2-methyl-3-[2-(4morpholinyl)ethyl]-1H-indole] and AM1710 [1-hydroxy-9-methoxy-3-(2-methyloctan-2yl)benzo[c]chromen-6-one], demonstrate that they are indeed dual $\mathrm{CB}_{2}$ agonists and $\mathrm{CB}_{1}$ antagonists [205]. Although not yet investigated as an antiobesity therapeutic, AM1710 is not brain penetrant [206], which is suggestive of a potential therapeutic that warrants further investigation. Recently, a dual target peripheral $\mathrm{CB}_{1}$ antagonist/iNOS inhibitor was reported to be effective in mitigating liver fibrosis, reducing bodyweight, hepatic steatosis and improving glucose tolerance in mice without inducing anxiety-like behavior $[207,208]$. A list of the emerging therapeutics is provided in Table 1. 


\section{Concluding remarks}

Obesity and metabolic disease constitute a major health burden throughout the world. ECS dysfunction has been identified in several target organs where expression of the ECS is altered in metabolic disease. $\mathrm{CB}_{1}$ is abundantly expressed in the brain, and globally targeting $\mathrm{CB}_{1}$ leads to significant adverse outcomes. $\mathrm{CB}_{2}$ is more abundant in the periphery, including the immune cells. Research using isolated cells in culture or tissues has demonstrated that modulation of the ECS in the periphery might be a potential therapeutic for metabolic disease. More-recent identification of peripheral specific CB ligands can reverse aspects of the metabolic phenotype. Further, dual CB ligands could be investigated as a potential therapeutic. Further work on the ECS is warranted for the targeting of metabolic disease.

\section{Acknowledgments}

We gratefully acknowledge the support of the Allen Foundation (USA) for our research in this area (D.H.H. and A.J.M.). Scholarship and fellowship funding is provided by Griffith University International Postgraduate Research Scholarship (GUIPRS-NS), the Griffith Health Top Up Scholarship (NS) and the Griffith University Postgraduate Research fellowship (GUPF-JSMC). 


\section{References}

1 Di Marzo, V. et al. (2009) The endocannabinoid system as a link between homoeostatic and hedonic pathways involved in energy balance regulation. Int. J. Obes. 33 (suppl. 2), 18-24

2 Pertwee, R.G. (2005) The therapeutic potential of drugs that target cannabinoid receptors or modulate the tissue levels or actions of endocannabinoids. AAPS J. 7, E625-654

3 Pertwee, R.G. (2008) Ligands that target cannabinoid receptors in the brain: from THC to anandamide and beyond. Addict. Biol. 13, 147-159 Spigelman, I. (2010) Frontiers in neuroscience: therapeutic targeting of peripheral cannabinoid receptors in inflammatory and neuropathic pain states. In Translational Pain Research: From Mouse to Man (Kruger, L. and Light, A.R., eds), CRC Press/Taylor \& Francis

Galiegue, S. et al. (1995) Expression of central and peripheral cannabinoid receptors in human immune tissues and leukocyte subpopulations. Eur. J. Biochem. 232, 54-61

6 Gong, J.P. et al. (2006) Cannabinoid CB2 receptors: immunohistochemical localization in rat brain. Brain Res. 1071, 10-23

7 Idris, A.I. and Ralston, S.H. (2012) Role of cannabinoids in the regulation of bone remodeling. Front. Endocrinol. 3, 136

8 Bab, l. et al. (2009) Cannabinoids and the skeleton: from marijuana to reversal of bone loss. Ann. Med. 41, 560-567

$9 \quad$ McHugh, D. et al. (2012) Delta(9)-tetrahydrocannabinol and $\mathrm{N}$-arachidonyl glycine are full agonists at GPR18 receptors and induce migration in human endometrial HEC-1B cells. Br. J. Pharmacol. 165, 2414-2424

10 Chu, Z.L. et al. (2010) N-Oleoyldopamine enhances glucose homeostasis through the activation of GPR119. Mol. Endocrinol. 24, 161-170

11 Martinez-Pinilla, E. et al. (2014) CB1 and GPR55 receptors are co-expressed and form heteromers in rat and monkey striatum. Exp. Neurol. 261, 44-52

$12 \mathrm{Kargl,}$ J. et al. (2012) The cannabinoid receptor CB1 modulates the signaling properties of the lysophosphatidylinositol receptor GPR55. J. Biol. Chem. 287, 44234-44248

13 Balenga, N.A. et al. (2014) Heteromerization of GPR55 and cannabinoid CB2 receptors modulates signalling. Br. J. Pharmacol. 171, 5387-5406

14 De Petrocellis, L. et al. (2011) Effects of cannabinoids and cannabinoid-enriched cannabis extracts on TRP channels and endocannabinoid metabolic enzymes. Br. J. Pharmacol. 163, 1479-1494

15 Hejazi, N. et al. (2006) Delta9-tetrahydrocannabinol and endogenous cannabinoid anandamide directly potentiate the function of glycine receptors. Mol. Pharmacol. 69, 991997

16 Huffman, J.W. et al. (1996) Synthesis and pharmacology of a very potent cannabinoid lacking a phenolic hydroxyl with high affinity for the CB2 receptor. J. Med. Chem. 39, 3875-3877

17 Svizenska, l. et al. (2008) Cannabinoid receptors 1 and 2 (CB1 and CB2), their distribution, ligands and functional involvement in nervous system structures--a short review. Pharmacol. Biochem. Behav. 90, 501-511

18 Pertwee, R.G. (2008) The diverse CB1 and CB2 receptor pharmacology of three plant cannabinoids: delta9-tetrahydrocannabinol, cannabidiol and delta9-tetrahydrocannabivarin. Br. J. Pharmacol. 153, 199-215

19 Bloom, A.S. et al. (1997) Nonclassical and endogenous cannabinoids: effects on the ordering of brain membranes. Neurochemical Res. 22, 563-568

20 Pertwee, R.G. (2006) The pharmacology of cannabinoid receptors and their ligands: an overview. Int. J. Obes. 30 (suppl. 1), 13-18 
21 Devane, W.A. et al. (1992) Isolation and structure of a brain constituent that binds to the cannabinoid receptor. Science 258, 1946-1949

22 Sugiura, T. et al. (1995) 2-Arachidonoylglycerol: a possible endogenous cannabinoid receptor ligand in brain. Biochem. Biophys. Res. Commun. 215, 89-97

23 Ibsen, M.S. et al. (2017) Cannabinoid CB1 and CB2 receptor signaling and bias. Cannabis Cannabinoid Res. 2, 48-60

24 Laprairie, R.B. et al. (2016) Biased type 1 cannabinoid receptor signaling influences neuronal viability in a cell culture model of Huntington disease. Mol. Pharmacol. 89, 364-375

25 Khajehali, E. et al. (2015) Biased agonism and biased allosteric modulation at the CB1 cannabinoid receptor. Mol. Pharmacol. 88, 368-379

26 Soethoudt, M. et al. (2017) Cannabinoid CB2 receptor ligand profiling reveals biased signalling and off-target activity. Nat. Commun. 8, 13958

27 Dhopeshwarkar, A. and Mackie, K. (2016) Functional selectivity of CB2 cannabinoid receptor ligands at a canonical and noncanonical pathway. J. Pharmacol. Exp. Ther. 358, 342-351

28 Tibirica, E. (2010) The multiple functions of the endocannabinoid system: a focus on the regulation of food intake. Diabetol. Metab. Syndr. 2, 5

29 Kim, J. et al. (2011) Endocannabinoid signaling and energy metabolism: a target for dietary intervention. Nutrition 27, 624-632

30 Matias, I. and Di Marzo, V. (2007) Endocannabinoids and the control of energy balance. Trends Endocrinol. Metab. 18, 27-37

31 Bermudez-Silva, F.J. et al. (2010) The endocannabinoid system, eating behavior and energy homeostasis: the end or a new beginning? Pharmacol. Biochem. Behav. 95, 375-382

32 Kola, B. et al. (2008) The orexigenic effect of ghrelin is mediated through central activation of the endogenous cannabinoid system. PLoS One 3, e1797

33 Di Marzo, V. et al. (2001) Leptin-regulated endocannabinoids are involved in maintaining food intake. Nature 410, 822-825

34 Pagotto, U. et al. (2006) The emerging role of the endocannabinoid system in endocrine regulation and energy balance. Endocr. Rev. 27, 73-100

35 Jamshidi, N. and Taylor, D.A. (2001) Anandamide administration into the ventromedial hypothalamus stimulates appetite in rats. Br. J. Pharmacol. 134, 1151-1154

36 Colombo, G. et al. (1998) Appetite suppression and weight loss after the cannabinoid antagonist SR 141716. Life Sci. 63, 113-117

37 Quarta, C. et al. (2010) CB(1) signaling in forebrain and sympathetic neurons is a key determinant of endocannabinoid actions on energy balance. Cell Metab. 11, 273-285

38 Ravinet Trillou, C. et al. (2004) CB1 cannabinoid receptor knockout in mice leads to leanness, resistance to diet-induced obesity and enhanced leptin sensitivity. Int. J. Obes. Relat. Metab. Disord. 28, 640-648

39 Cota, D. et al. (2003) Endogenous cannabinoid system as a modulator of food intake. Int. J. Obes. Relat. Metab. Disord. 27, 289-301

40 Lan, R. et al. (1999) Design and synthesis of the CB1 selective cannabinoid antagonist AM281: a potential human SPECT ligand. AAPS PharmSci 1, 39-45

41 Landsman, R.S. et al. (1997) SR141716A is an inverse agonist at the human cannabinoid CB1 receptor. Eur. J. Pharmacol. 334, R1-2

42 Smaga, I. et al. (2014) The endocannabinoid/endovanilloid system and depression. Curr. Neuropharmacol. 12, 462-474

43 Pagotto, U. et al. (2005) The endocannabinoid system and the treatment of obesity. Ann. Med. 37, 270-275

44 Bensaid, M. et al. (2003) The cannabinoid CB1 receptor antagonist SR141716 increases Acrp30 mRNA expression in adipose tissue of obese fa/fa rats and in cultured adipocyte cells. Mol. Pharmacol. 63, 908-914 
Pacher, P. and Mechoulam, R. (2011) Is lipid signaling through cannabinoid 2 receptors part of a protective system? Prog. Lipid Res. 50, 193-211

46 Alvheim, A.R. et al. (2012) Dietary linoleic acid elevates endogenous 2-AG and anandamide and induces obesity. Obesity 20, 1984-1994

47 Bluher, M. et al. (2006) Dysregulation of the peripheral and adipose tissue endocannabinoid system in human abdominal obesity. Diabetes 55, 3053-3060

48 Cote, M. et al. (2007) Circulating endocannabinoid levels, abdominal adiposity and related cardiometabolic risk factors in obese men. Int. J. Obes. 31, 692-699

49 Abdulnour, J. et al. (2014) Circulating endocannabinoids in insulin sensitive vs. insulin resistant obese postmenopausal women. A MONET group study. Obesity 22, 211-216 Van Gaal, L.F. et al. (2005) Effects of the cannabinoid-1 receptor blocker rimonabant on weight reduction and cardiovascular risk factors in overweight patients: 1-year experience from the RIO-Europe study. Lancet 365, 1389-1397

51 Scherer, T. and Buettner, C. (2009) The dysregulation of the endocannabinoid system in diabesity-a tricky problem. J. Mol. Med. 87, 663-668

52 Niki, M. et al. (2015) Modulation of sweet taste sensitivities by endogenous leptin and endocannabinoids in mice. J. Physiol. 593, 2527-2545

53 Cheung, C.C. et al. (1997) Proopiomelanocortin neurons are direct targets for leptin in the hypothalamus. Endocrinology 138, 4489-4492

54 Tam, J. et al. (2017) Peripheral cannabinoid-1 receptor blockade restores hypothalamic leptin signaling. Mol. Metab. 6, 1113-1125

55 Tam, J. et al. (2012) Peripheral cannabinoid-1 receptor inverse agonism reduces obesity by reversing leptin resistance. Cell Metab. 16, 167-179 Jo, Y.H. et al. (2005) Integration of endocannabinoid and leptin signaling in an appetiterelated neural circuit. Neuron 48, 1055-1066

57 Malcher-Lopes, R. et al. (2006) Opposing crosstalk between leptin and glucocorticoids rapidly modulates synaptic excitation via endocannabinoid release. J. Neurosci. 26, 66436650

58 Buettner, C. et al. (2008) Leptin controls adipose tissue lipogenesis via central, STAT3independent mechanisms. Nat. Med. 14, 667-675

59 Costa, M.A. et al. (2015) 2-Arachidonoylglycerol impairs human cytotrophoblast cells syncytialization: influence of endocannabinoid signalling in placental development. Mol. Cell. Endocrinol. 399, 386-394

60 Lowell, B.B. and Shulman, G.I. (2005) Mitochondrial dysfunction and type 2 diabetes. Science 307, 384-387

61 Bhatti, J.S. et al. (2017) Mitochondrial dysfunction and oxidative stress in metabolic disorders - a step towards mitochondria based therapeutic strategies. Biochim. Biophys. Acta 1863, 1066-1077

62 Lipina, C. et al. (2014) Mitochondria: a possible nexus for the regulation of energy homeostasis by the endocannabinoid system? Am. J. Physiol. Endocrinol. Metab. 307, E1-13

63 Catanzaro, G. et al. (2009) Anandamide increases swelling and reduces calcium sensitivity of mitochondria. Biochem. Biophys. Res. Commun. 388, 439-442

64 Costa, M.A. et al. (2015) The endocannabinoid anandamide induces apoptosis in cytotrophoblast cells: involvement of both mitochondrial and death receptor pathways. Placenta 36, 69-76

65 Zaccagnino, P. et al. (2011) Anandamide inhibits oxidative phosphorylation in isolated liver mitochondria. FEBS Lett. 585, 429-434

66 Athanasiou, A. et al. (2007) Cannabinoid receptor agonists are mitochondrial inhibitors: a unified hypothesis of how cannabinoids modulate mitochondrial function and induce cell death. Biochem. Biophys. Res. Commun. 364, 131-137 
67 Tedesco, L. et al. (2008) Cannabinoid type 1 receptor blockade promotes mitochondrial biogenesis through endothelial nitric oxide synthase expression in white adipocytes. Diabetes 57, 2028-2036

68 Alonso, M. et al. (2012) Anti-obesity efficacy of LH-21, a cannabinoid CB(1) receptor antagonist with poor brain penetration, in diet-induced obese rats. Br. J. Pharmacol. 165, 2274-2291

69 Mendizabal-Zubiaga, J. et al. (2016) Cannabinoid CB1 receptors are localized in striated muscle mitochondria and regulate mitochondrial respiration. Front. Physiol. 7, 476

70 Benard, G. et al. (2012) Mitochondrial CB(1) receptors regulate neuronal energy metabolism. Nat. Neurosci. 15, 558-564

71 Hebert-Chatelain, E. et al. (2016) A cannabinoid link between mitochondria and memory. Nature 539, 555-559

72 Koch, M. et al. (2015) Hypothalamic POMC neurons promote cannabinoid-induced feeding. Nature 519, 45-50

73 Siegmund, S.V. et al. (2007) The endocannabinoid 2-arachidonoyl glycerol induces death of hepatic stellate cells via mitochondrial reactive oxygen species. Faseb J. 21, 2798-2806

74 Jeong, W.I. et al. (2008) Paracrine activation of hepatic CB1 receptors by stellate cell-derived endocannabinoids mediates alcoholic fatty liver. Cell Metab. 7, 227-235

75 Mukhopadhyay, B. et al. (2010) Transcriptional regulation of cannabinoid receptor-1 expression in the liver by retinoic acid acting via retinoic acid receptor-gamma. J. Biol. Chem. 285, 19002-19011

76 Mendez-Sanchez, N. et al. (2007) Endocannabinoid receptor CB2 in nonalcoholic fatty liver disease. Liver Int. 27, 215-219

77 Julien, B. et al. (2005) Antifibrogenic role of the cannabinoid receptor CB2 in the liver. Gastroenterology 128, 742-755

$78 \mathrm{Xu}, \mathrm{X}$. et al. (2006) Overexpression of cannabinoid receptors CB1 and CB2 correlates with improved prognosis of patients with hepatocellular carcinoma. Cancer Genet. Cytogenet. $171,31-38$

79 Zelber-Sagi, S. et al. (2017) Serum levels of endocannabinoids are independently associated with nonalcoholic fatty liver disease. Obesity 25, 94-101

80 Osei-Hyiaman, D. et al. (2005) Endocannabinoid activation at hepatic CB1 receptors stimulates fatty acid synthesis and contributes to diet-induced obesity. J. Clin. Invest. 115, 1298-1305

81 Osei-Hyiaman, D. et al. (2008) Hepatic CB1 receptor is required for development of dietinduced steatosis, dyslipidemia, and insulin and leptin resistance in mice. J. Clin. Invest. 118, 3160-3169

82 Jourdan, T. et al. (2010) CB1 antagonism exerts specific molecular effects on visceral and subcutaneous fat and reverses liver steatosis in diet-induced obese mice. Diabetes 59, 926934

83 Gary-Bobo, M. et al. (2007) Rimonabant reduces obesity-associated hepatic steatosis and features of metabolic syndrome in obese Zucker fa/fa rats. Hepatology 46, 122-129

84 Wu, H.M. et al. (2011) Rimonabant, a cannabinoid receptor type 1 inverse agonist, inhibits hepatocyte lipogenesis by activating liver kinase B1 and AMP-activated protein kinase axis downstream of Galpha i/o inhibition. Mol. Pharmacol. 80, 859-869

85 Shi, D. et al. (2014) Inhibiting CB1 receptors improves lipogenesis in an in vitro non-alcoholic fatty liver disease model. Lipids Health Dis. 13, 173

86 Tam, J. et al. (2014) Role of adiponectin in the metabolic effects of cannabinoid type 1 receptor blockade in mice with diet-induced obesity. Am. J. Physiol. Endocrinol. Metab. 306, E457-468

87 Liu, J. et al. (2012) Hepatic cannabinoid receptor-1 mediates diet-induced insulin resistance via inhibition of insulin signaling and clearance in mice. Gastroenterology 142, 1218-1228 
Cinar, R. et al. (2014) Hepatic cannabinoid-1 receptors mediate diet-induced insulin resistance by increasing de novo synthesis of long-chain ceramides. Hepatology 59, 143-153 Deveaux, V. et al. (2009) Cannabinoid CB2 receptor potentiates obesity-associated inflammation, insulin resistance and hepatic steatosis. PLoS One 4, e5844 De Gottardi, A. et al. (2010) Cannabinoid receptor 1 and 2 agonists increase lipid accumulation in hepatocytes. Liver Int. 30, 1482-1489

91 Kusminski, C.M. et al. (2016) Targeting adipose tissue in the treatment of obesity-associated diabetes. Nat. Rev. Drug Discov. 15, 639-660

92 Guerre-Millo, M. (2002) Adipose tissue hormones. J. Endocrinol. Invest. 25, 855-861

93 Cota, D. et al. (2003) The endogenous cannabinoid system affects energy balance via central orexigenic drive and peripheral lipogenesis. J. Clin. Invest. 112, 423-431

94 Engeli, S. et al. (2005) Activation of the peripheral endocannabinoid system in human obesity. Diabetes 54, 2838-2843

95 Cable, J.C. et al. (2011) The activity of the endocannabinoid metabolising enzyme fatty acid amide hydrolase in subcutaneous adipocytes correlates with BMI in metabolically healthy humans. Lipids Health Dis. 10, 129

96 Motaghedi, R. and McGraw, T.E. (2008) The CB1 endocannabinoid system modulates adipocyte insulin sensitivity. Obesity 16, 1727-1734

97 Pagano, C. et al. (2007) The endogenous cannabinoid system stimulates glucose uptake in human fat cells via phosphatidylinositol 3-kinase and calcium-dependent mechanisms. J. Clin. Endocrinol. Metab. 92, 4810-4819

98 Perwitz, N. et al. (2010) Cannabinoid type 1 receptor blockade induces transdifferentiation towards a brown fat phenotype in white adipocytes. Diabetes Obes. Metab. 12, 158-166

99 Bajzer, M. et al. (2011) Cannabinoid receptor 1 (CB1) antagonism enhances glucose utilisation and activates brown adipose tissue in diet-induced obese mice. Diabetologia 54, 3121-3131

100 Varbo, A. et al. (2015) Remnant cholesterol, low-density lipoprotein cholesterol, and blood pressure as mediators from obesity to ischemic heart disease. Circ. Res. 116, 665-673

101 Lepicier, P. et al. (2003) Endocannabinoids protect the rat isolated heart against ischaemia. Br. J. Pharmacol. 139, 805-815

102 Di Filippo, C. et al. (2004) Cannabinoid CB2 receptor activation reduces mouse myocardial ischemia-reperfusion injury: involvement of cytokine/chemokines and PMN. J. Leukoc. Biol. 75, 453-459

103 Montecucco, F. et al. (2009) CB(2) cannabinoid receptor activation is cardioprotective in a mouse model of ischemia/reperfusion. J. Mol. Cell. Cardiol. 46, 612-620

104 Defer, N. et al. (2009) The cannabinoid receptor type 2 promotes cardiac myocyte and fibroblast survival and protects against ischemia/reperfusion-induced cardiomyopathy. Faseb J. 23, 2120-2130

105 Wang, P.F. et al. (2012) Cannabinoid-2 receptor activation protects against infarct and ischemia-reperfusion heart injury. J. Cardiovasc. Pharmacol. 59, 301-307

106 Slavic, S. et al. (2013) Cannabinoid receptor 1 inhibition improves cardiac function and remodelling after myocardial infarction and in experimental metabolic syndrome. J. Mol. Med. 91, 811-823

107 Steffens, S. et al. (2005) Low dose oral cannabinoid therapy reduces progression of atherosclerosis in mice. Nature 434, 782-786

108 Montecucco, F. et al. (2009) Regulation and possible role of endocannabinoids and related mediators in hypercholesterolemic mice with atherosclerosis. Atherosclerosis 205, 433-441

109 Dol-Gleizes, F. et al. (2009) Rimonabant, a selective cannabinoid CB1 receptor antagonist, inhibits atherosclerosis in LDL receptor-deficient mice. Arterioscler. Thromb. Vasc. Biol. 29, 12-18 
110 Tiyerili, V. et al. (2010) CB1 receptor inhibition leads to decreased vascular AT1 receptor expression, inhibition of oxidative stress and improved endothelial function. Basic Res. Cardiol. 105, 465-477

111 Montecucco, F. et al. (2008) CB2 cannabinoid receptor agonist JWH-015 modulates human monocyte migration through defined intracellular signaling pathways. Am. J. Physiol. Heart Circ. Physiol. 294, H1145-1155

112 Hoyer, F.F. et al. (2011) Atheroprotection via cannabinoid receptor-2 is mediated by circulating and vascular cells in vivo. J. Mol. Cell. Cardiol. 51, 1007-1014

113 Rajesh, M. et al. (2008) CB2 cannabinoid receptor agonists attenuate TNF-alpha-induced human vascular smooth muscle cell proliferation and migration. Br. J. Pharmacol. 153, 347357

114 Netherland-Van Dyke, C. et al. (2015) Cannabinoid receptor type 2 (CB2) dependent and independent effects of WIN55,212-2 on atherosclerosis in Ldlr-null mice. J. Cardiol. Ther. 3, 53-63

115 Cavuoto, P. et al. (2007) Effects of cannabinoid receptors on skeletal muscle oxidative pathways. Mol. Cell. Endocrinol. 267, 63-69

116 Cavuoto, P. et al. (2007) The expression of receptors for endocannabinoids in human and rodent skeletal muscle. Biochem. Biophys. Res. Commun. 364, 105-110

117 Liu, Y.L. et al. (2005) Effects of the cannabinoid CB1 receptor antagonist SR141716 on oxygen consumption and soleus muscle glucose uptake in Lep(ob)/Lep(ob) mice. Int. J. Obes. 29, 183-187

118 Lindborg, K.A. et al. (2010) Effects of in vitro antagonism of endocannabinoid-1 receptors on the glucose transport system in normal and insulin-resistant rat skeletal muscle. Diabetes Obes. Metab. 12, 722-730

119 Crespillo, A. et al. (2011) Expression of the cannabinoid system in muscle: effects of a highfat diet and CB1 receptor blockade. Biochem. J. 433, 175-185

120 Engeli, S. et al. (2014) Influence of dietary fat intake on the endocannabinoid system in lean and obese subjects. Obesity 22, E70-76

121 Hutchins-Wiese, H.L. et al. (2012) Hind limb suspension and long-chain omega-3 PUFA increase mRNA endocannabinoid system levels in skeletal muscle. J. Nutr. Biochem. 23, 986993

122 Yki-Jarvinen, H. et al. (1987) Regulation of glycogen synthase and phosphorylase activities by glucose and insulin in human skeletal muscle. J. Clin. Invest. 80, 95-100

123 Eckardt, K. et al. (2011) Obesity-associated insulin resistance in skeletal muscle: role of lipid accumulation and physical inactivity. Rev. Endocr. Metab. Disord. 12, 163-172

124 Eckardt, K. et al. (2009) Cannabinoid type 1 receptors in human skeletal muscle cells participate in the negative crosstalk between fat and muscle. Diabetologia 52, 664-674

125 Lindborg, K.A. et al. (2011) Effects of chronic antagonism of endocannabinoid-1 receptors on glucose tolerance and insulin action in skeletal muscles of lean and obese Zucker rats. Cardiorenal. Med. 1, 31-44

126 Lipina, C. et al. (2010) Regulation of MAP kinase-directed mitogenic and protein kinase Bmediated signaling by cannabinoid receptor type 1 in skeletal muscle cells. Diabetes 59, 375-385

127 Di Carlo, G. and Izzo, A.A. (2003) Cannabinoids for gastrointestinal diseases: potential therapeutic applications. Expert Opin. Investig. Drugs 12, 39-49

128 McVey, D.C. et al. (2003) Endocannabinoids induce ileitis in rats via the capsaicin receptor (VR1). J. Pharmacol. Exp. Ther. 304, 713-722

129 Massa, F. and Monory, K. (2006) Endocannabinoids and the gastrointestinal tract. J. Endocrinol. Invest. 29 (3 suppl.), 47-57

130 Mechoulam, R. et al. (1995) Identification of an endogenous 2-monoglyceride, present in canine gut, that binds to cannabinoid receptors. Biochem. Pharmacol. 50, 83-90 
131 Izzo, A.A. et al. (2001) Cannabinoid CB1-receptor mediated regulation of gastrointestinal motility in mice in a model of intestinal inflammation. Br. J. Pharmacol. 134, 563-570

132 Wright, K. et al. (2005) Differential expression of cannabinoid receptors in the human colon: cannabinoids promote epithelial wound healing. Gastroenterology 129, 437-453

133 Tschop, M. et al. (2000) Ghrelin induces adiposity in rodents. Nature 407, 908-913

134 Kola, B. et al. (2005) Cannabinoids and ghrelin have both central and peripheral metabolic and cardiac effects via AMP-activated protein kinase. J. Biol. Chem. 280, 25196-25201

135 Tucci, S.A. et al. (2004) The cannabinoid CB1 receptor antagonist SR141716 blocks the orexigenic effects of intrahypothalamic ghrelin. Br. J. Pharmacol. 143, 520-523

136 Alen, F. et al. (2013) Ghrelin-induced orexigenic effect in rats depends on the metabolic status and is counteracted by peripheral CB1 receptor antagonism. PLoS One 8, e60918

137 Senin, L.L. et al. (2013) The gastric CB1 receptor modulates ghrelin production through the mTOR pathway to regulate food intake. PLoS One 8, e80339

138 Kola, B. et al. (2013) The CB1 receptor mediates the peripheral effects of ghrelin on AMPK activity but not on growth hormone release. Faseb J. 27, 5112-5121

139 Burdyga, G. et al. (2004) Expression of cannabinoid CB1 receptors by vagal afferent neurons is inhibited by cholecystokinin. J. Neurosci. 24, 2708-2715

140 Juan-Pico, P. et al. (2006) Cannabinoid receptors regulate $\mathrm{Ca}(2+)$ signals and insulin secretion in pancreatic beta-cell. Cell. Calcium 39, 155-162

141 Bermudez-Silva, F.J. et al. (2008) Presence of functional cannabinoid receptors in human endocrine pancreas. Diabetologia 51, 476-487

142 Matias, l. et al. (2006) Regulation, function, and dysregulation of endocannabinoids in models of adipose and beta-pancreatic cells and in obesity and hyperglycemia. J. Clin. Endocrinol. Metab. 91, 3171-3180

143 Getty-Kaushik, L. et al. (2009) The CB1 antagonist rimonabant decreases insulin hypersecretion in rat pancreatic islets. Obesity 17, 1856-1860

144 Li, C. et al. (2011) Cannabinoid receptor agonists and antagonists stimulate insulin secretion from isolated human islets of Langerhans. Diabetes Obes. Metab. 13, 903-910

$145 \mathrm{Kim}$, W. et al. (2011) Cannabinoids inhibit insulin receptor signaling in pancreatic beta-cells. Diabetes 60, 1198-1209

146 Jourdan, T. et al. (2013) Activation of the Nlrp3 inflammasome in infiltrating macrophages by endocannabinoids mediates beta cell loss in type 2 diabetes. Nat. Med. 19, 1132-1140

147 Jourdan, T. et al. (2017) Developmental role of macrophage cannabinoid-1 receptor signaling in type 2 diabetes. Diabetes 66, 994-1007

148 Deutsch, D.G. and Chin, S.A. (1993) Enzymatic synthesis and degradation of anandamide, a cannabinoid receptor agonist. Biochem. Pharmacol. 46, 791-796

149 Barutta, F. et al. (2010) Cannabinoid receptor 1 blockade ameliorates albuminuria in experimental diabetic nephropathy. Diabetes 59, 1046-1054

150 Lin, C.L. et al. (2014) Cannabinoid receptor 1 disturbance of PPARgamma2 augments hyperglycemia induction of mesangial inflammation and fibrosis in renal glomeruli. J. Mol. Med. 92, 779-792

151 Koura, Y. et al. (2004) Anandamide decreases glomerular filtration rate through predominant vasodilation of efferent arterioles in rat kidneys. J. Am. Soc. Nephrol. 15, 14881494

152 Lecru, L. et al. (2015) Cannabinoid receptor 1 is a major mediator of renal fibrosis. Kidney Int. $88,72-84$

153 Silva, G.B. et al. (2013) Anandamide inhibits transport-related oxygen consumption in the loop of Henle by activating CB1 receptors. Am. J. Physiol. Renal Physiol. 304, F376-381

154 Larrinaga, G. et al. (2010) Expression of cannabinoid receptors in human kidney. Histol. Histopathol. 25, 1133-1138 
155 Jenkin, K.A. et al. (2012) Endocannabinoids and the renal proximal tubule: an emerging role in diabetic nephropathy. Int. J. Biochem. Cell. Biol. 44, 2028-2031

156 Ejerblad, E. et al. (2006) Obesity and risk for chronic renal failure. J. Am. Soc. Nephrol. 17, 1695-1702

157 Hsu, C.Y. et al. (2006) Body mass index and risk for end-stage renal disease. Ann. Intern. Med. 144, 21-28

158 Jenkin, K.A. et al. (2015) Chronic administration of AM251 improves albuminuria and renal tubular structure in obese rats. J. Endocrinol. 225, 113-124

159 Udi, S. et al. (2017) Proximal tubular cannabinoid-1 receptor regulates obesity-induced CKD. J. Am. Soc. Nephrol. 28, 3518-3532

160 Jenkin, K.A. et al. (2016) Renal effects of chronic pharmacological manipulation of CB2 receptors in rats with diet-induced obesity. Br. J. Pharmacol. 173, 1128-1142

161 Jenkin, K.A. et al. (2013) Cannabinoid receptor 2 expression in human proximal tubule cells is regulated by albumin independent of ERK1/2 signaling. Cell Physiol. Biochem. 32, 1309-1319

162 Tanasescu, R. and Constantinescu, C.S. (2010) Cannabinoids and the immune system: an overview. Immunobiology 215, 588-597

163 Turcotte, C. et al. (2015) Regulation of inflammation by cannabinoids, the endocannabinoids 2-arachidonoyl-glycerol and arachidonoyl-ethanolamide, and their metabolites. J. Leukoc. Biol. 97, 1049-1070

164 McCoy, K.L. (2016) Interaction between cannabinoid system and Toll-like receptors controls inflammation. Mediators Inflamm. 2016, 5831315

165 Despres, J.P. et al. (2005) Effects of rimonabant on metabolic risk factors in overweight patients with dyslipidemia. N. Engl. J. Med. 353, 2121-2134

166 Kabir, M. et al. (2015) CB1R antagonist increases hepatic insulin clearance in fat-fed dogs likely via upregulation of liver adiponectin receptors. Am. J. Physiol. Endocrinol. Metab. 309, E747-758

167 Murumalla, R. et al. (2011) Effect of the cannabinoid receptor-1 antagonist SR141716A on human adipocyte inflammatory profile and differentiation. J. Inflamm. 8, 33

$168 \mathrm{Ge}$, Q. et al. (2013) Endocannabinoids regulate adipokine production and the immune balance of omental adipose tissue in human obesity. Int. J. Obes. 37, 874-880

169 Rajesh, M. et al. (2007) CB2-receptor stimulation attenuates TNF-alpha-induced human endothelial cell activation, transendothelial migration of monocytes, and monocyteendothelial adhesion. Am. J. Physiol. Heart Circ. Physiol. 293, H2210-2218

170 Wilhelmsen, K. et al. (2014) The endocannabinoid/endovanilloid $N$-arachidonoyl dopamine (NADA) and synthetic cannabinoid WIN55,212-2 abate the inflammatory activation of human endothelial cells. J. Biol. Chem. 289, 13079-13100

171 Jean-Gilles, L. et al. (2015) Effects of pro-inflammatory cytokines on cannabinoid CB1 and CB2 receptors in immune cells. Acta Physiol. 214, 63-74

172 Borner, C. et al. (2007) Transcriptional regulation of the cannabinoid receptor type 1 gene in T cells by cannabinoids. J. Leukoc. Biol. 81, 336-343

173 Borner, C. et al. (2008) Analysis of promoter regions regulating basal and interleukin-4inducible expression of the human CB1 receptor gene in T lymphocytes. Mol. Pharmacol. 73, 1013-1019

174 Lou, Z.Y. et al. (2011) Targeting CB(2) receptor as a neuroinflammatory modulator in experimental autoimmune encephalomyelitis. Mol. Immunol. 49, 453-461

175 Lou, Z.Y. et al. (2012) Immunoregulation of experimental autoimmune encephalomyelitis by the selective CB1 receptor antagonist. J. Neurosci. Res. 90, 84-95

176 Batkai, S. et al. (2007) Cannabinoid-2 receptor mediates protection against hepatic ischemia/reperfusion injury. Faseb J. 21, 1788-1800

177 Caraceni, P. et al. (2009) Antagonism of the cannabinoid CB-1 receptor protects rat liver against ischaemia-reperfusion injury complicated by endotoxaemia. Gut 58, 1135-1143 
178 Berdyshev, E. et al. (1998) Effects of cannabinoid receptor ligands on LPS-induced pulmonary inflammation in mice. Life Sci 63, 125-129

179 Comelli, F. et al. (2007) The inhibition of monoacylglycerol lipase by URB602 showed an antiinflammatory and anti-nociceptive effect in a murine model of acute inflammation. Br. J. Pharmacol. 152, 787-794

180 Naidu, P.S. et al. (2010) Regulation of inflammatory pain by inhibition of fatty acid amide hydrolase. J. Pharmacol. Exp. Ther. 334, 182-190

181 Csoka, B. et al. (2009) CB2 cannabinoid receptors contribute to bacterial invasion and mortality in polymicrobial sepsis. PLoS One 4, e6409

182 Mestre, L. et al. (2005) Pharmacological modulation of the endocannabinoid system in a viral model of multiple sclerosis. J. Neurochem. 92, 1327-1339

183 Liu, Y.J. et al. (2013) Cannabinoid receptor 2 suppresses leukocyte inflammatory migration by modulating the JNK/c-Jun/Alox5 pathway. J. Biol. Chem. 288, 13551-13562

184 Hasko, J. et al. (2014) CB2 receptor activation inhibits melanoma cell transmigration through the blood-brain barrier. Int. J. Mol. Sci. 15, 8063-8074

185 Berdyshev, E.V. et al. (1997) Influence of fatty acid ethanolamides and delta9tetrahydrocannabinol on cytokine and arachidonate release by mononuclear cells. Eur. J. Pharmacol. 330, 231-240

186 Cencioni, M.T. et al. (2010) Anandamide suppresses proliferation and cytokine release from primary human T-lymphocytes mainly via CB2 receptors. PLoS One 5, e8688

187 Guillot, A. et al. (2014) Cannabinoid receptor 2 counteracts interleukin-17-induced immune and fibrogenic responses in mouse liver. Hepatology 59, 296-306

188 Coopman, K. et al. (2007) Temporal variation in CB2R levels following T lymphocyte activation: evidence that cannabinoids modulate CXCL12-induced chemotaxis. Int. Immunopharmacol. 7, 360-371

189 Basu, S. et al. (2011) Cannabinoid receptor 2 is critical for the homing and retention of marginal zone B lineage cells and for efficient T-independent immune responses. J. Immunol. $187,5720-5732$

190 Muppidi, J.R. et al. (2011) Cannabinoid receptor 2 positions and retains marginal zone B cells within the splenic marginal zone. J. Exp. Med. 208, 1941-1948

191 Agudelo, M. et al. (2008) Cannabinoid receptor 2 (CB2) mediates immunoglobulin class switching from IgM to IgE in cultures of murine-purified B lymphocytes. J. Neuroimmune Pharmacol. 3, 35-42

192 Basu, S. et al. (2013) Cannabinoid receptor 2 (CB2) plays a role in the generation of germinal center and memory B cells, but not in the production of antigen-specific IgG and IgM, in response to T-dependent antigens. PLoS One 8, e67587

193 Gui, H. et al. (2013) Cannabinoid receptor 2 protects against acute experimental sepsis in mice. Mediators Inflamm. 2013, 741303

194 Mukhopadhyay, P. et al. (2010) CB1 cannabinoid receptors promote oxidative stress and cell death in murine models of doxorubicin-induced cardiomyopathy and in human cardiomyocytes. Cardiovasc. Res. 85, 773-784

195 Oka, S. et al. (2006) Involvement of the cannabinoid CB2 receptor and its endogenous ligand 2-arachidonoylglycerol in oxazolone-induced contact dermatitis in mice. J. Immunol. 177, 8796-8805

196 Gokoh, M. et al. (2005) 2-arachidonoylglycerol, an endogenous cannabinoid receptor ligand, induces rapid actin polymerization in HL-60 cells differentiated into macrophage-like cells. Biochem. J. 386, 583-589

197 Cluny, N.L. et al. (2010) A novel peripherally restricted cannabinoid receptor antagonist, AM6545, reduces food intake and body weight, but does not cause malaise, in rodents. Br. J. Pharmacol. 161, 629-642 
198 Argueta, D.A. and DiPatrizio, N.V. (2017) Peripheral endocannabinoid signaling controls hyperphagia in western diet-induced obesity. Physiol. Behav. 171, 32-39

199 Tam, J. et al. (2010) Peripheral CB1 cannabinoid receptor blockade improves cardiometabolic risk in mouse models of obesity. J. Clin. Invest. 120, 2953-2966

200 Bowles, N.P. et al. (2015) A peripheral endocannabinoid mechanism contributes to glucocorticoid-mediated metabolic syndrome. Proc. Natl. Acad. Sci. U. S. A. 112, 285-290

201 Knani, l. et al. (2016) Targeting the endocannabinoid/CB1 receptor system for treating obesity in Prader-Willi syndrome. Mol. Metab. 5, 1187-1199

202 Pavon, F.J. et al. (2006) Antiobesity effects of the novel in vivo neutral cannabinoid receptor antagonist 5-(4-chlorophenyl)-1-(2,4-dichlorophenyl)-3-hexyl-1H-1,2,4-triazole--LH 21. Neuropharmacology 51, 358-366

203 Lu, Y. et al. (2014) Ligand activation of cannabinoid receptors attenuates hypertrophy of neonatal rat cardiomyocytes. J. Cardiovasc. Pharmacol. 64, 420-430

204 Cluny, N.L. et al. (2010) Naphthalen-1-yl-(4-pentyloxynaphthalen-1-yl)methanone (SAB378), a peripherally restricted cannabinoid $C B 1 / C B 2$ receptor agonist, inhibits gastrointestinal motility but has no effect on experimental colitis in mice. J. Pharmacol. Exp. Ther. 334, 973980

205 Dhopeshwarkar, A. et al. (2017) Two Janus cannabinoids that are both CB2 agonists and CB1 antagonists. J. Pharmacol. Exp. Ther. 360, 300-311

206 Rahn, E.J. et al. (2011) Pharmacological characterization of AM1710, a putative cannabinoid CB2 agonist from the cannabilactone class: antinociception without central nervous system side-effects. Pharmacol. Biochem. Behav. 98, 493-502

207 Cinar, R. et al. (2016) Hybrid inhibitor of peripheral cannabinoid-1 receptors and inducible nitric oxide synthase mitigates liver fibrosis. JCl Insight 1, 11

208 Iyer, M.R. et al. (2017) Design, synthesis, and biological evaluation of novel, non-brainpenetrant, hybrid cannabinoid CB1R inverse agonist/inducible nitric oxide synthase (iNOS) inhibitors for the treatment of liver fibrosis. J. Med. Chem. 60, 1126-1141

209 Klumpers, L.E. et al. (2013) Peripheral selectivity of the novel cannabinoid receptor antagonist TM38837 in healthy subjects. Br. J. Clin. Pharmacol. 76, 846-857

210 Son, M.H. et al. (2010) Peripherally acting CB1-receptor antagonist: the relative importance of central and peripheral CB1 receptors in adiposity control. Int. J. Obes. 34, 547-556

211 Hsiao, W.C. et al. (2015) A novel peripheral cannabinoid receptor 1 antagonist, BPR0912, reduces weight independently of food intake and modulates thermogenesis. Diabetes Obes. Metab. 17, 495-504

212 LoVerme, J. et al. (2009) Synthesis and characterization of a peripherally restricted CB1 cannabinoid antagonist, URB447, that reduces feeding and body-weight gain in mice. Bioorg. Med. Chem. Lett. 19, 639-643 


\section{Authors Biographies}

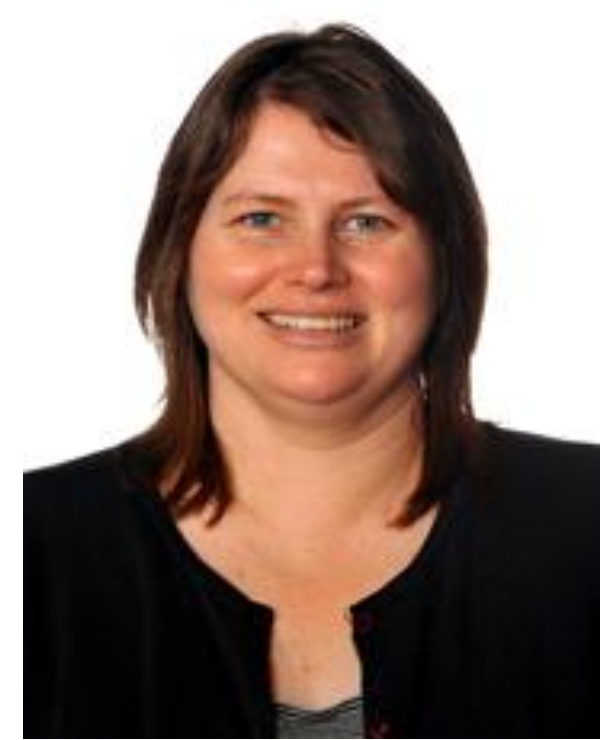

Deanne Hryciw

Deanne Hryciw is currently a senior lecturer in the Menzies Health Institute Queensland at Griffith University. She received her PhD in cellular physiology from University of South Australia. Her current research interests cover the endocannabinoid system, with a particular focus on altered peripheral systems in obesity. She is also interested in developmental programming, and the modulation of maternal dietary elements in programming offspring health. She has published over 50 peer-reviewed journal articles and referenced conference proceedings and book chapters. She has presented her research at national and international invited lectures on endocannabinoid signaling in obesity and leptin.

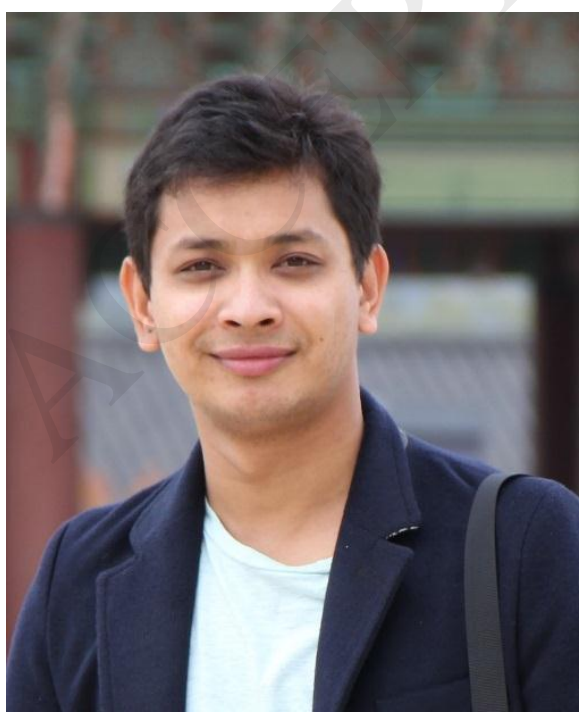




\section{Nirajan Shrestha}

Nirajan Shrestha is currently doing his PhD at Menzies Health Institute Queensland at Griffith University, Australia. He has done his MS in biomedical science from Chonbuk National University, South Korea and his BS in medical biochemistry from Pokhara University, Nepal. His current research focuses on the effect of maternal diet in offspring health. He is also interested in fatty acid metabolism, the endocannabinoid system and metabolic diseases. He has published three peer-reviewed journal articles and presented his research at different national and international conferences. 


\section{Figure legends}

Figure 1. Biosynthesis, degradation and metabolism of endocannabinoids. Abbreviations: $A A$, arachidonic acid; AEA, $\mathrm{N}$-arachidonoylethanolamine; 2-AG, 2-arachidonoylglycerol; NAPEPLD, $N$-acyl phosphatidylethanolamine-specific phospholipase D; DAGL, diacylglycerol lipase; MAGL, monoacylglycerol lipase; AC, adenylyl cyclase; AMPK, 5' adenosine monophosphateactivated protein kinase; PKA, protein kinase A; NOS, nitric oxide synthase; FA, fatty acid.

Figure 2. Peripheral modulation of the endocannabinoid system (ECS). Abbreviations: FA, fatty acid; SREBP-1, sterol regulatory element-binding protein 1; LPL, lipoprotein lipase; GI tract, gastrointestinal tract. 


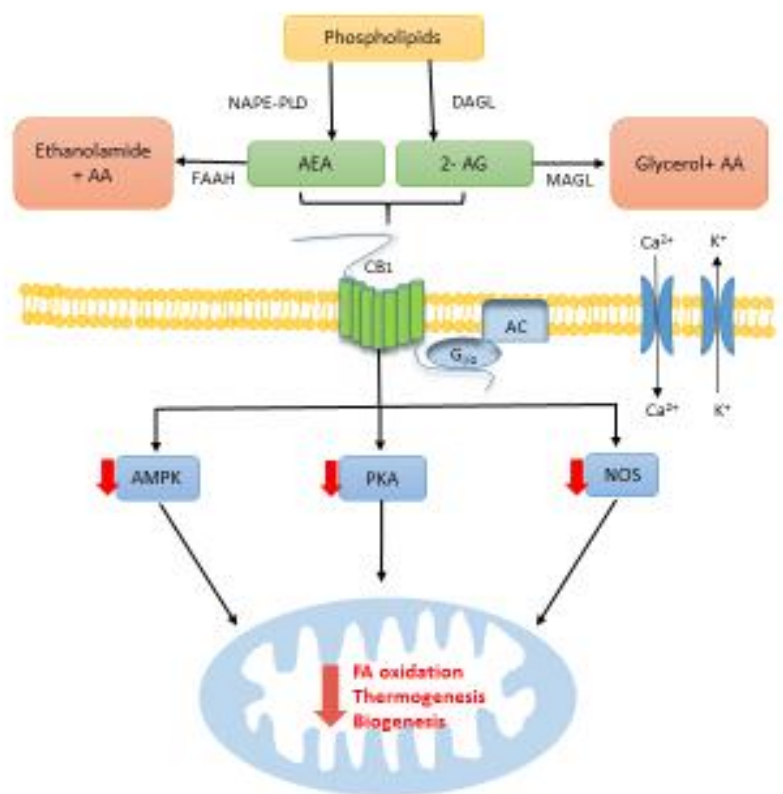




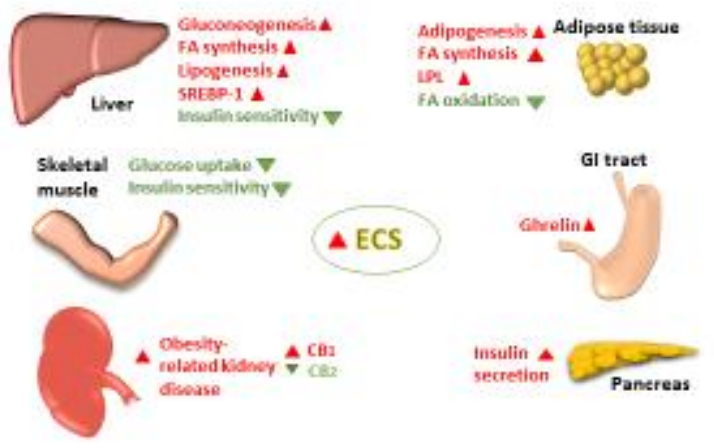


Table 1. Novel therapeutic targets modulating ECS for the treatment of obesity and metabolic disease 


\begin{tabular}{|c|c|c|c|c|c|}
\hline SN & Compound & Chemical structure & Target & Effects & Refs \\
\hline 1 & AM6545 & $\mathrm{N}_{3}$ & $\begin{array}{l}\text { Peripherally restricted } \mathrm{CB}_{1} \text { neutral } \\
\text { antagonist }\end{array}$ & $\begin{array}{l}\text { Reduce food intake and bodyweight } \\
\text { Improve dyslipidaemia by activating BAT }\end{array}$ & [197] \\
\hline 2 & TM38837 & & $\begin{array}{l}\text { Peripherally selective } \mathrm{CB}_{1} \text { inverse } \\
\text { agonist }\end{array}$ & $\begin{array}{l}\text { Predicated to improve metabolic profile } \\
\text { (Currently in Phase I clinical trial) }\end{array}$ & [209] \\
\hline 3 & JD5037 & & $\begin{array}{l}\text { Peripherally selective } \mathrm{CB}_{1} \text { inverse } \\
\text { agonist }\end{array}$ & $\begin{array}{l}\text { Attenuate glucose intolerance and insulin } \\
\text { resistance } \\
\text { Reverse leptin resistance }\end{array}$ & [199] \\
\hline 4 & Compound-1 & & Peripheral $\mathrm{CB}_{1}$ selective antagonist & $\begin{array}{l}\text { Reduce food intake and bodyweight } \\
\text { Decrease hepatic SREBP- } 1 c^{b}\end{array}$ & [210] \\
\hline 5 & LH-21 & & $\begin{array}{l}\text { Neutral } \mathrm{CB}_{1} \text { antagonist (poor brain } \\
\text { penetration) }\end{array}$ & $\begin{array}{l}\text { Decrease food intake and bodyweight } \\
\text { Reduce lipogenic enzymes }\end{array}$ & [202] \\
\hline
\end{tabular}




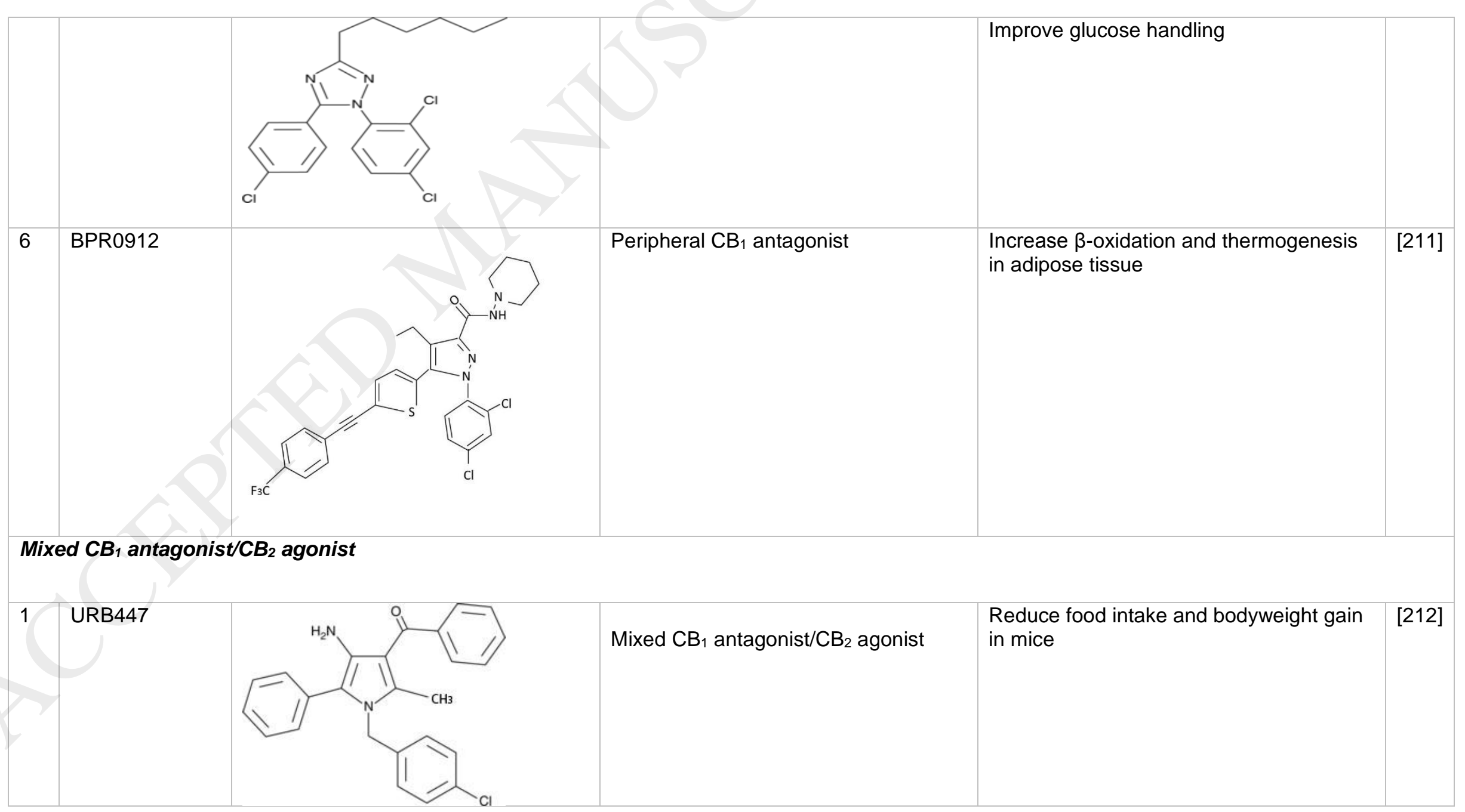




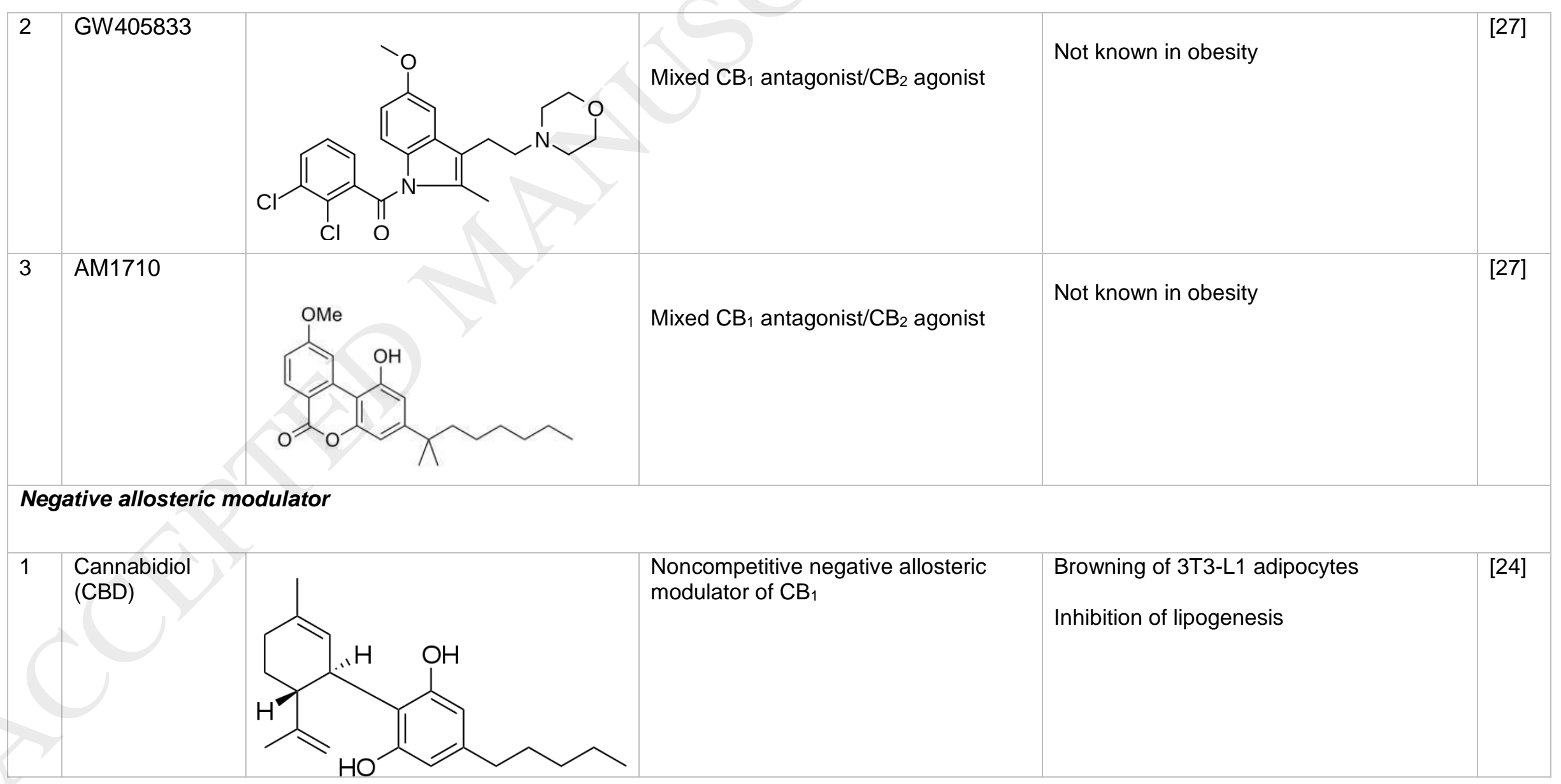

aBrown adipose tissue.

bSterol regulatory-element-binding protein 1. 


\section{Accepted Manuscript}

Title: Peripheral modulation of the endocannabinoid system in metabolic disease

Authors: Nirajan Shrestha, James S.M. Cuffe, Dana S.

Hutchinson, John P. Headrick, Anthony V. Perkins, Andrew J. McAinch, Deanne H. Hryciw

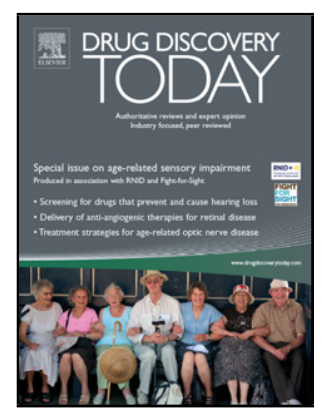

PII: S1359-6446(17)30415-4

DOI: $\quad$ https://doi.org/10.1016/j.drudis.2018.01.029

Reference: $\quad$ DRUDIS 2162

To appear in:

Please cite this article as: Shrestha, Nirajan, Cuffe, James S.M., Hutchinson, Dana S., Headrick, John P., Perkins, Anthony V., McAinch, Andrew J., Hryciw, Deanne H., Peripheral modulation of the endocannabinoid system in metabolic disease.Drug Discovery Today https://doi.org/10.1016/j.drudis.2018.01.029

This is a PDF file of an unedited manuscript that has been accepted for publication. As a service to our customers we are providing this early version of the manuscript. The manuscript will undergo copyediting, typesetting, and review of the resulting proof before it is published in its final form. Please note that during the production process errors may be discovered which could affect the content, and all legal disclaimers that apply to the journal pertain. 